\title{
Iron Oxide and Gold Based Magneto-Plasmonic Nanostructures for Medical Applications: A Review
}

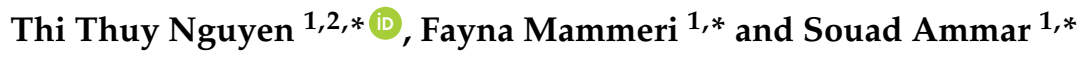 \\ 1 Interfaces, Traitements, Organisation et Dynamique des Systèmes, ITODYS, UMR 7086, CNRS, \\ Université Paris Diderot, Sorbonne Paris Cité, 15 rue Jean Antoine de Baif, 75205 Paris, France \\ 2 Department of Advanced Materials Science and Nanotechnology, \\ University of Science and Technology of Hanoi, Vietnam Academy of Science and Technology, \\ 18 Hoang Quoc Viet, Hanoi, Vietnam \\ * Correspondence: thi.nguyen46@etu.univ-paris-diderot.fr (T.T.N.); \\ fayna.mammeri@univ-paris-diderot.fr (F.M.); ammarmer@univ-paris-diderot.fr (S.A.); \\ Tel.: +33-1-5727-8843 (F.M.); +33-1-5727-8609 (S.A.)
}

Received: 22 December 2017; Accepted: 26 February 2018; Published: 7 March 2018

\begin{abstract}
Iron oxide and gold-based magneto-plasmonic nanostructures exhibit remarkable optical and superparamagnetic properties originating from their two different components. As a consequence, they have improved and broadened the application potential of nanomaterials in medicine. They can be used as multifunctional nanoprobes for magneto-plasmonic heating as well as for magnetic and optical imaging. They can also be used for magnetically assisted optical biosensing, to detect extreme traces of targeted bioanalytes. This review introduces the previous work on magneto-plasmonic hetero-nanostructures including: (i) their synthesis from simple "one-step" to complex "multi-step" routes, including seed-mediated and non-seed-mediated methods; and (ii) the characterization of their multifunctional features, with a special emphasis on the relationships between their synthesis conditions, their structures and their properties. It also focuses on the most important progress made with regard to their use in nanomedicine, keeping in mind the same aim, the correlation between their morphology—namely spherical and non-spherical, core-satellite and core-shell, and the desired applications.
\end{abstract}

Keywords: magneto-plasmonic; nanocrystals; spherical; non-spherical; core-satellite; seed-mediated

\section{Introduction}

Iron oxide nanoparticles (NPs) of a maghemite $\left(\mathrm{Fe}_{2.67} \mathrm{O}_{4}\right)$ or magnetite $\left(\mathrm{Fe}_{3} \mathrm{O}_{4}\right)$ composition have demonstrated their strong potential for diagnostic and therapeutic applications due to their unique magnetic properties [1-3]. Indeed, these NPs can be used as contrast enhancement agents in magnetic resonance imaging (MRI). They can also generate heat under an external alternating magnetic field, making them valuable for magnetic hyperthermia therapy [4-6]. Besides, they can be guided and immobilized close to a specific biological target thanks to an external dc magnetic field for magnetically assisted drug delivery. Highly magnetized superparamagnetic NPs are a good choice for all these diagnostic and/or therapeutic uses. As high is the magnetization of these NPs, as high is their magnetic response to an external magnetic stimulus and as high is their efficiency in electromagnetically assisted nanomedicine.

Gold NPs exhibit also strong unique and tunable optical properties including Mie scattering, surface plasmonic resonance (SPR), surface-enhanced luminescence and surface Raman scattering. Moreover, gold surface is nontoxic and chemically stable under physiological conditions. It can be easily functionalized through thiol groups leading to Au-SH (gold-thiol) bio-conjugation for various ligands using immune targeting as biomarkers. Nowadays, they are used for high sensitivity and 
high resolution optical imaging [7,8]. Their multiplexing capabilities make them also valuable for bio-sensing [9-13]. More recently, they started to be employed for in vivo photothermal therapy [14-18], particularly when their SPR wavelength is in the near-infrared region (NIR), to avoid body tissues light scattering.

Many attentions have been focused on the strategies for the fabrication of multifunctional nanostructures (NSs), combining ether the magnetic or the plasmonic properties of iron oxide or gold NPs, respectively, to the biological activities of selected biomolecules attached at their surface. For example, molecular functionalization of magnetic or plasmonic NPs by antibodies, proteins and/or organic ligands allows the production of nanohybrids exhibiting both physical and biological properties. This interest has also concerned the integration of magnetic NPs and other functional solids, like quantum dots (QDs) and noble metals (gold, silver ... ) [13,15,17,19-21] in single nano-objects, potentially stimulated by both magnetic and electrical fields, providing simultaneously magnetic and optical responses. Focusing on this kind of probes, a rapid overview of the relevant literature shows that they are commonly prepared by (i) coupling two particle populations, exhibiting either magnetic or optical properties, and embedding them in a same biocompatible polymer or ceramic matrix; (ii) coagulating both magnetic and optical, mainly plasmonic, NPs or (iii) performing a sequential growth of the two components, forming thus well-architected NSs of various morphologies (core-shell, raspberry, etc.) $[13,22]$.

In the first chemical strategy, polymeric or ceramic matrix, which possesses colloidal stability and low cytotoxicity, constitutes the main component of the material carrier. It offers a protective layer from aggregation and/or oxidation to the embedded NPs. In addition, incorporation of molecular dyes and/or drugs inside the carriers provides advantages for a wide range of biomedical applications [23-27]. This kind of NSs is usually produced by the self-assembly (or sol-gel process) of polymer and silica wrap to preformed functional NPs, including iron oxide and gold particles.

In the second strategy, the produced aggregates [28-33] including hollow aggregates, possess random and polydispersed NPs of iron oxide and plasmonic NPs, mainly gold. These structures are built thanks to a strong metal-oxide interaction at the interface of the two kinds of involved particles. Hollow ones provide high specific surface and low density [30-33], leading to an interest in the field of high drug-loading capacity. In addition, their plasmonic components exhibit not only a superior surface-enhanced Raman scattering (SERS) sensitivity, but also an excellent catalytic activity [28,29].

In the third strategy, the serial growth material processing is privileged. The competition between homogeneous and heterogeneous nucleation mechanisms represents the main issue affecting the morphology of the engineered NSs. In other words, starting from a seed phase is crucial to promote an exclusive growth of the new phase on the surface of the former. The promotion of heterogeneous nucleation while suppressing homogeneous one can be achieved by adjusting the reaction parameters such as the temperature, the precursor atomic ratio, the reaction time, the $\mathrm{pH}$, among others. In these conditions and only in these conditions, uniformly distributed in size core-satellite or core-shell NSs can be produced. These sequentially grown $\mathrm{Fe}_{3-x} \mathrm{O}_{4}(x=0$ for magnetite and $x=0.33$ for maghemite) on $\mathrm{Au}$, or reversely $\mathrm{Au}$ on $\mathrm{Fe}_{3-x} \mathrm{O}_{4}$, NSs are very probably the most investigated multifunctional platforms for biomedicine. They have been naturally considered as dual heating sources as well as dual imaging probes. Beside their remarkable optical and magnetic properties provided by their plasmonic and superparamagnetic components, they offer the benefit of the control of their physical properties and then, their whole response to any external electromagnetic stimulus, through the control of their synthesis conditions. Indeed, the chemical composition, size and shape adjustment of each component achieved by the control of each synthesis parameter affects directly the plasmonic absorption wavelength and intensity of the built NSs as well as their total magnetization and their average blocking temperature value.

So, we propose in this review to summarize the recent achievements in the preparation of this last type of NSs, distinguishing the objects made from iron oxide cores surrounded by gold either as 
satellites or as a continuous shell and reversely, those made from gold cores surrounded by iron oxide either as satellites or as a continuous shell.

Many chemical and physical routes have been proposed to prepare such NSs, but chemical deposition processes are certainly the most employed ones. They consist in direct deposition of seeds on preformed cores followed by a controlled growth of the seeds to form a more or less continuous coating around them. So, the main achievements of the literature in this research area are described hereafter, with a special emphasis on the most important progress made on their use in nanomedicine, with always the same aim, the correlation between their morphology and their properties. The review will be thus organized in three mains sections, a first one dedicated to the preparation of $\mathrm{Fe}_{3-x} \mathrm{O}_{4}-\mathrm{Au}$ (FANSs) and $\mathrm{Au}-\mathrm{Fe}_{3-x} \mathrm{O}_{4}$ (AFNSs) NSs, respectively, a second one focusing on their magneto-plasmonic properties in relation to their structure and microstructure, and finally a third one describing their main use in biomedicine, in relation with their physical properties.

\section{Structure and Synthesis of Magneto-Plasmonic Nanostructures Based on a Sequential Growth in Solution}

\section{1. $\mathrm{Fe}_{3-x} \mathrm{O}_{4}-\mathrm{Au}$ Nanostructures (FANSs)}

The most described magneto-plasmonic NSs are the FANSs, consisting in a $\mathrm{Fe}_{3-x} \mathrm{O}_{4}$ single core or multicores on whose surface Au coating agents have been attached, allowing the growth of a continuous or discontinuous Au shell. FANSs can be spherical or non-spherical in shape (nanospheres, nanorods, nanoflowers, nanostars ... ). Their magnetic properties are mainly driven by the chemical composition (maghemite or magnetite), the size and the architecture of their core component (single core or multicores) while their plasmonic properties are mainly defined by the shape of their Au layer component. Interestingly, thanks to their gold surface that can be easily functionalized by thiol groups making FANSs conjugated to various biological molecules is easy. Gold surface reactivity toward various hydrophilic ligands and polymers allows also convenient surface functionalization of FANSs improving their biocompatibility and their aqueous colloidal stability. Moreover, the gold layer acts as a protection layer toward chemical oxidation, preserving, hence, the intrinsic properties of the core material, and as a diamagnetic layer, limiting magnetic mutual attraction and preventing from FANSs agglomeration and flocculation in a solution.

FANSs are mainly used in scattering based imaging producing high sensitivity, high resolution and multiplexing capability. They are also used as contrast agent for MRI and heating sources for magnetic hyperthermia.

\subsubsection{Different FANS Architectures}

The different structures of FANSs can be listed according to the shape of Au shell and divided into 4 types: (a) core-satellites; (b) spherical core-shell; (c) non-spherical core-shell and (d) spherical and non-spherical hollow structures (Figure 1).

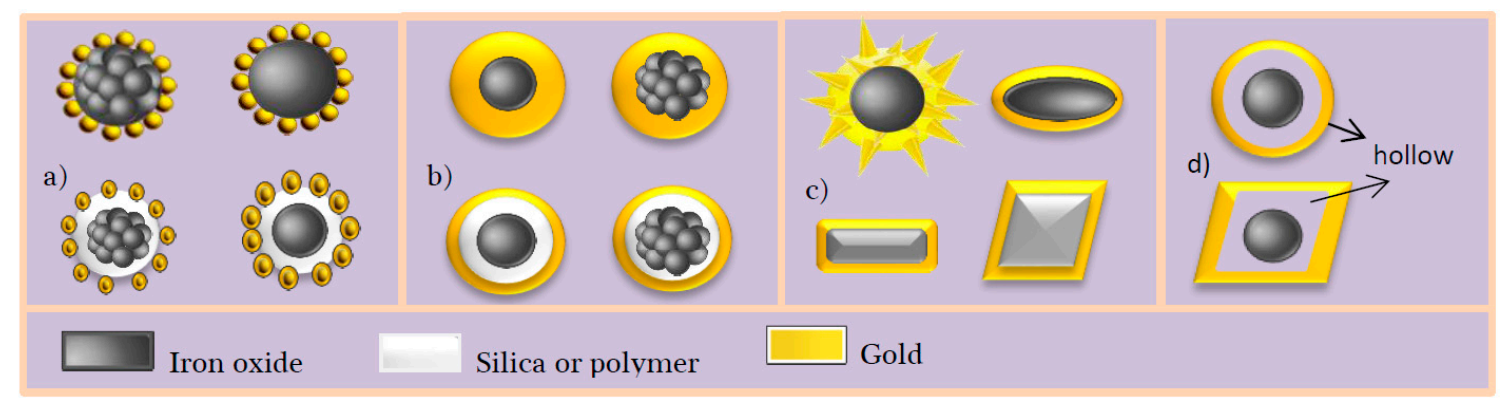

Figure 1. Main engineered structures of $\mathrm{Fe}_{3-x} \mathrm{O}_{4}-\mathrm{Au}$ Nanostructures (FANSs): (a) core-satellites; (b) spherical core-shell; (c) non-spherical core-shell and (d) hollow structures. 
$\mathrm{Fe}_{3-x} \mathrm{O}_{4}$-Au Core-Satellite Structure

$\mathrm{Fe}_{3-x} \mathrm{O}_{4}$-Au core-satellite structure is defined as a particle with a single or multi $\mathrm{Fe}_{3-x} \mathrm{O}_{4}$ cores surrounded by several $\mathrm{Au}$ small particles. The gold coating does not cover the whole $\mathrm{Fe}_{3-x} \mathrm{O}_{4}$ component surface, forming a satellite-type layer all around. The main advantage of such morphology is to provide a high gold specific area and to offer the possibility of a further functionalization of the uncovered $\mathrm{Fe}_{3-x} \mathrm{O}_{4}$ surface, eventually different from that engaged on Au surface. FANSs can also be employed as seeds to grow a complete Au layer, leading to $\mathrm{Fe}_{3-x} \mathrm{O}_{4}$-Au core-shell structures.

Spherical $\mathrm{Fe}_{3-x} \mathrm{O}_{4}$-Au Core-Shell Structure

$\mathrm{Fe}_{3-x} \mathrm{O}_{4}$-Au spherical core-shell structure includes a single or multi $\mathrm{Fe}_{3-x} \mathrm{O}_{4}$ cores completely covered by a gold spherical shell. Compared to the core-satellite structure, the core-shell one exhibits lowest magnetization due to a higher diamagnetic contribution of gold, but an improved stability and biocompatibility in aqueous media. Indeed, the $\mathrm{Fe}_{3-x} \mathrm{O}_{4}$ cores are fully covered by $\mathrm{Au}$, making them chemically inert, even in corrosive environments like biological ones. In addition, based on the Mie theory, the optical properties of these structures are quite different from those of individual $\mathrm{Au}$ spherical NPs. Therefore, by only varying the ratio between the $\mathrm{Fe}_{3-x} \mathrm{O}_{4}$ core size and the $\mathrm{Au}$ shell thickness, it becomes possible to easily tune the SPR gold response from visible to near-infrared region.

Non-Spherical $\mathrm{Fe}_{3-x} \mathrm{O}_{4}$-Au Core-Shell Structure

Non-spherical $\mathrm{Fe}_{3-x} \mathrm{O}_{4}$-Au core-shell particles are composed by $\mathrm{Fe}_{3-x} \mathrm{O}_{4}$ single or multi cores surrounded by a non-spherical Au coating, like stars. As previously, the outer gold shell covers the whole $\mathrm{Fe}_{3-x} \mathrm{O}_{4}$ surface and prevents thus its further oxidation and corrosion. It also increases the stability and the biocompatibility of the resulting material. Additionally, the anisotropic shape of the gold shell leads to unusual optical features that are difficult to achieve using spherical one. Typically, a shift of the plasmonic absorption wavelength to higher values, matching very well with the spectral body windows, can be observed, improving thus significantly the efficiency of the designed structures for in vivo biomedical applications.

$\mathrm{Fe}_{3-x} \mathrm{O}_{4}-\mathrm{Au}$ Hollow Structure

$\mathrm{Fe}_{3-x} \mathrm{O}_{4}$-Au hollow structures are mainly based on $\mathrm{Fe}_{3-x} \mathrm{O}_{4}$ spheres surrounded by Au wall with a hollow interior, leading to large specific area and high reactivity. Among $\mathrm{Fe}_{3-x} \mathrm{O}_{4}$-Au core-shell nanoparticles, Au's hollow structure have indicated the attractive SPR feature which can be tuned from visible to NIR by varying the size, shape, and structure of the gold shell. These structures include integration both the magnetic properties and optical properties of iron oxide core and gold shells. In addition, the hollow interior provides high specific surface, low density and the possibility of physically entrapping drugs. Drugs may be loaded by encapsulation inside the hollow structure or by surface attachment where drugs are conjugated to the inner or outer gold surfaces using labile bonds.

\subsubsection{FANS Synthesis}

There are various approaches to synthesize FANSs. One of the simplest consists of combining gold and iron oxide nanoparticles through an assembly process linking two separately prepared NPs. $\mathrm{Au}$ and $\mathrm{Fe}_{3-x} \mathrm{O}_{4}$ NPs are first functionalized by smart ligands, bearing in one side a group, which will be attached to the NP surface, and in the other side another functional group. For example, $\mathrm{Au}$ NPs attached through a thiol group to a ligand bearing negatively charged $-\mathrm{CO}_{2}{ }^{-}$species, and $\mathrm{Fe}_{3-x} \mathrm{O}_{4}$ NPs attached through a diol group to a ligand bearing positively charged $-\mathrm{NH}_{3}{ }^{+}$may interact electrostatically to form a robust $\mathrm{Fe}_{3-x} \mathrm{O}_{4}$-Au self-assembly. Negatively charged $\mathrm{Au}$ NPs (of 3-20 nm in diameter) can be easily synthesized in aqueous solution through the reduction of $\mathrm{HAuCl}_{4}$ by sodium citrate or $\mathrm{NaBH}_{4}[34,35]$, and subsequently electrostatically attached to $\mathrm{Fe}_{3-x} \mathrm{O}_{4}$ functionalized by positively charged amino groups. $\mathrm{Fe}_{3-x} \mathrm{O}_{4}$ NPs can be produced otherwise by 
thermal decomposition, aqueous co-precipitation, forced hydrolysis in polyol and solvothermal route. The former methods lead to the production of relatively small in size single crystals $(<50 \mathrm{~nm}$ in diameter), while the latter allows the production of larger in size single and/or polycrystals (30-400 nm) [36-42]. These NPs can be then modified by grafting organosilanes, phosphonic acids, diol or carboxylate-based ligands or polymers bearing amino terminal groups that can interact with Au NPs (Figure 2). Typically, 3-aminopropyltriethoxysilane (APTES) [34,37], dopamine [42], polyethylene imine (PEI) [35,36,40,41], L-cysteine [38], poly (methyleneimine) [43], poly-(diallyldimethyl ammonium chloride) [44], cysteamine [45] have been extensively used for such a purpose.

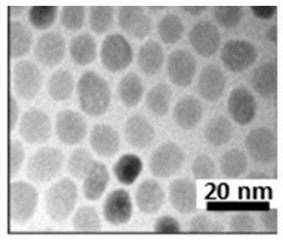

$\mathrm{Fe}_{3-\mathrm{x}} \mathrm{O}_{4}-\mathrm{NH}_{2}$

single core

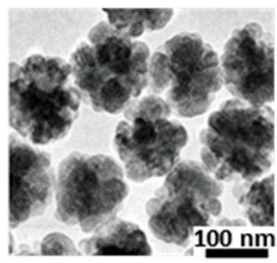

$\mathrm{Fe}_{3-\mathrm{x}} \mathrm{O}_{4}-\mathrm{NH}_{2}$
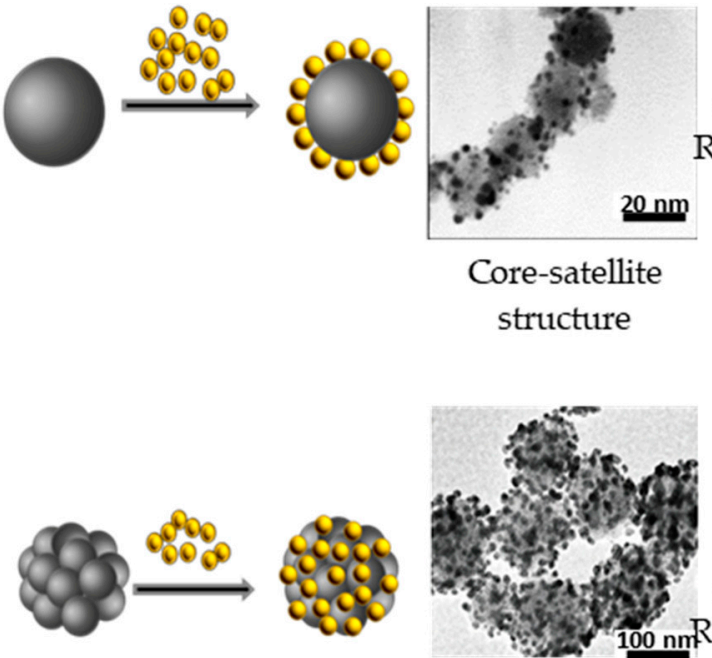

Core-satellite

structure

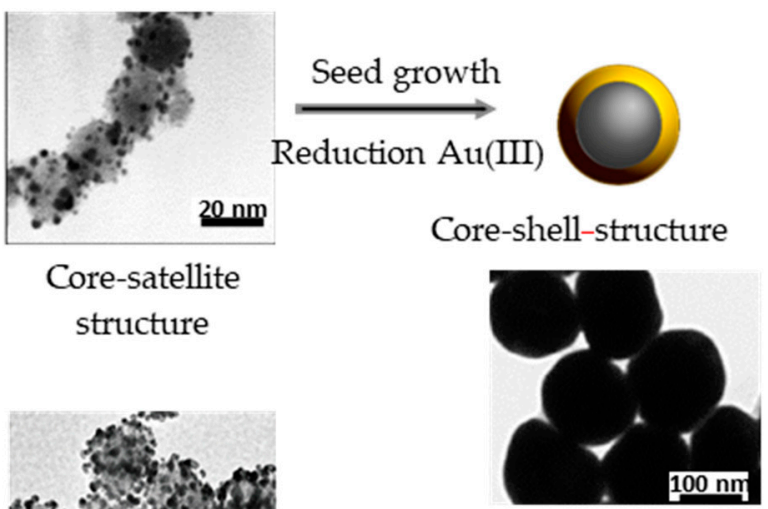

multicores

Figure 2. Schematic overview of the formation of core-satellite (top: reproduced with permission from [46]. American Chemical Society, 2005, and bottom: reproduced with permission from [47]. Royal Society of Chemistry, 2015) and core-shell spherical structure (representative TEM image reproduced with permission from [48], American Chemical Society, 2016).

Alternatively, magnetic single or multi cores can be coated by a uniform silica shell, and then modified with an amine group [10] (Figure 3).

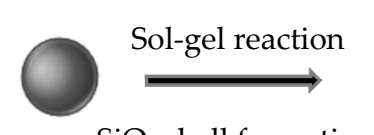

$\mathrm{SiO}_{2}$ shell formation

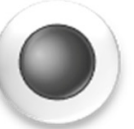

$\mathrm{Fe}_{3-\mathrm{x}} \mathrm{O}_{4} \mathrm{NPs}$
$\mathrm{Fe}_{3-\mathrm{x}} \mathrm{O}_{4}-\mathrm{SiO}_{2} \quad$ Core-shell-satellite Core-shell
Figure 3. Schematic view of the formation of a silica layer around an iron oxide core before the

\section{Amine coating}

Au NPs

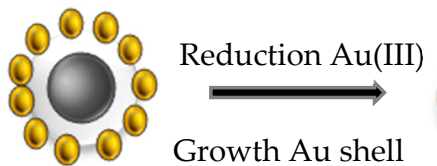

Growth Au shell

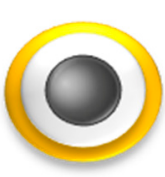

$\mathrm{Fe}_{3-\mathrm{x}} \mathrm{O}_{4} \mathrm{NPs}$
$\mathrm{Fe}_{3-\mathrm{x}} \mathrm{O}_{4}-\mathrm{SiO}_{2} \quad$ Core-shell-satellite Core-shell
Figure 3. Schematic view of the formation of a silica layer around an iron oxide core before the deposition of gold satellites and shell by seed-mediated growth.

The preparation of FANSs may also proceed by a chemical deposition process involving the direct reduction of dissolved $\mathrm{Au}(\mathrm{III})$ species onto the $\mathrm{Fe}_{3-x} \mathrm{O}_{4}$ surface according. In this case, two different chemical pathways may be followed. In a first one, the formed satellites act as nucleation points (seeds) for the subsequent continuous metallic layer growth, using formaldehydes [10,42], $N, N$-dimethylformamide (DMF) [40], $\mathrm{NaBH}_{4}$ [35], among others, as reducing agent. This method requires several steps but it allows the control of the Au shell morphology. Alternatively, iron oxide NPs can be first coated by silica, before the gold seeds attachment and the further continuous gold shell growth. Huang et al. [49] prepared, for instance, $\mathrm{Fe}_{3} \mathrm{O}_{4}$ multicores embedded in 
a $\mathrm{SiO}_{2}$ matrix by the Stöber method (Figure 4). Then, they functionalized the outer silica layer by 3-aminopropyltrimethoxysilane (APTMS), which electrostatically interacted with negatively charged preformed gold NPs. At the end, they used the as-produced products as platforms for gold shell growth via an in-situ reduction of chloroauric acid precursor by formaldehyde reagent.

(a)
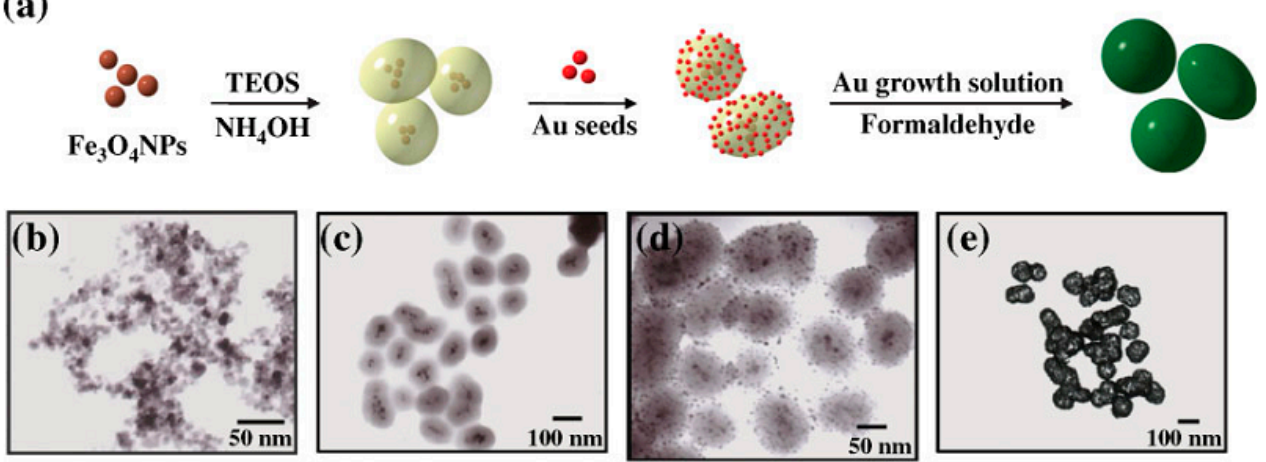

Figure 4. (a) Schematic representation of the preparation of $\mathrm{Fe}_{3} \mathrm{O}_{4}-\mathrm{Au}$ nanoeggs. TEM images of the (b) magnetic iron oxide NPs; (c) silica nanoeggs embedding magnetic iron oxide $\mathrm{NPs}\left(\mathrm{Fe}_{3} \mathrm{O}_{4}-\mathrm{SiO}_{2}\right)$; (d) gold nanoseeds bound to $\mathrm{Fe}_{3} \mathrm{O}_{4}-\mathrm{SiO}_{2} \mathrm{NPs}\left(\mathrm{Fe}_{3} \mathrm{O}_{4}-\mathrm{SiO}_{2}-\mathrm{Au}\right.$ ); and (e) $\mathrm{Fe}_{3} \mathrm{O}_{4}$-Au nanoeggs. Reproduced with permission from [49]. John Wiley and Sons, 2009.

A variety of shape and sizes of magnetic core NPs were synthesized by Halas et al. [36], using wustite FeO nanocrystals as precursors to form magnetic oxides of higher oxidation state, and to then grow a continuous gold shell layer all around. The coverage of the iron oxide surface by the gold shell was initiated by electrostatic interactions between the magnetic surface and the preformed negatively charged gold NPs, leading to a core-satellite architecture. Then, it was achieved by an in-situ reduction of auric cations at the surface of the gold seeds. At the end, whatever the morphology of the wustite precursors was, the morphology of the final core-shell particles was almost spherical (Figure 5).

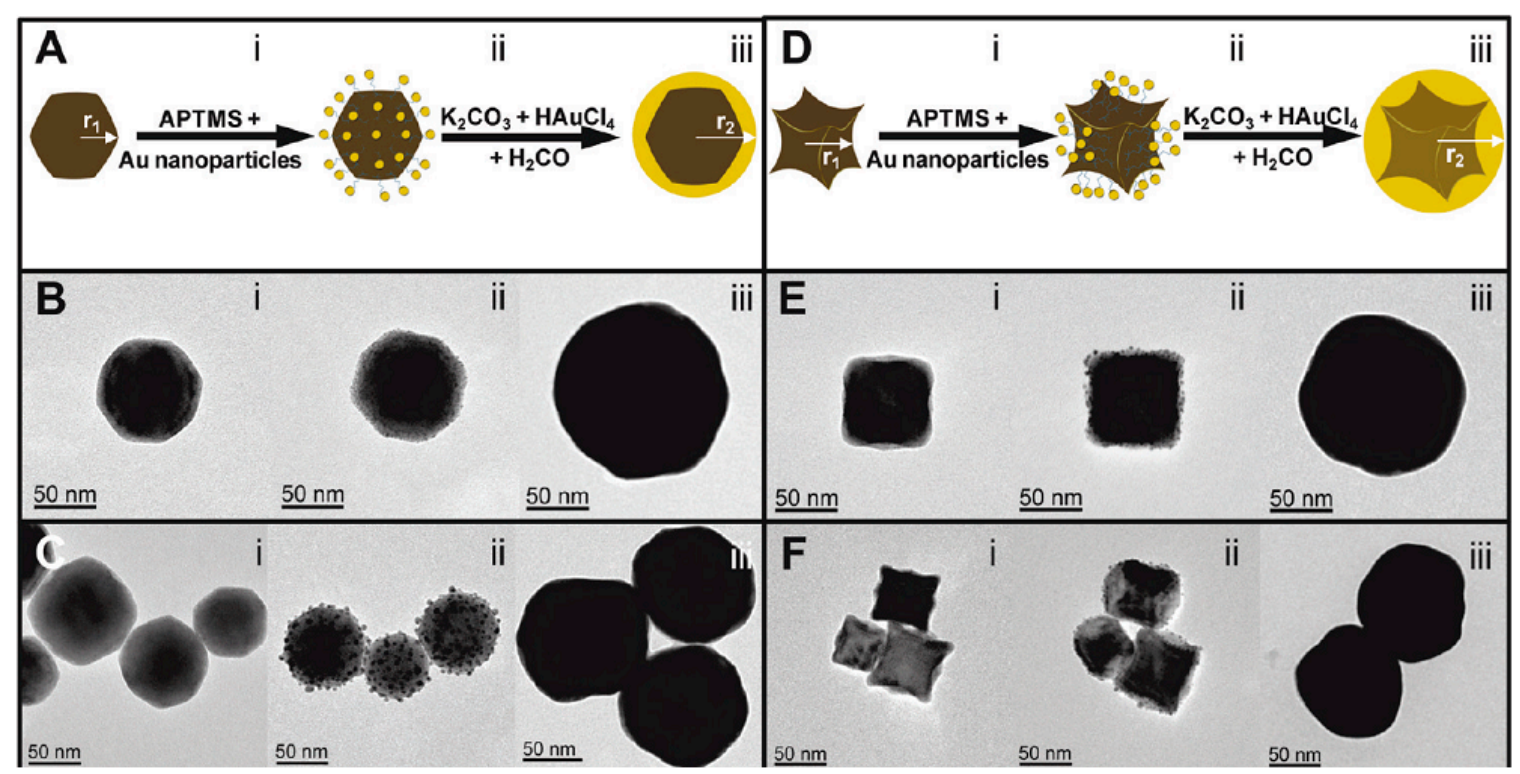

Figure 5. Schematic overview of the gold coating of (A-C) faceted and (D-F) tetracubic iron oxide cores. Representative TEM images of (i) the starting iron oxide cores; (ii) the decorated ones by Au precursors; and (iii) the coated ones by a continuous Au shell are given for illustration. Reproduced with permission from [50]. American Chemical Society, 2009. 
In the second route, called also one-step route, the $\mathrm{Fe}_{3-x} \mathrm{O}_{4}$ surface is directly coated by a gold layer [51,52]. This implies that $\mathrm{Au}$ atoms are directly deposited onto $\mathrm{Fe}_{3-x} \mathrm{O}_{4}$ through the reduction of $\mathrm{Au}(\mathrm{III})$ precursors (Figure 6). The basic principle for the formation of the gold shell is that $\mathrm{Fe}_{3-x} \mathrm{O}_{4}$ core surface must be appropriately charged to attract the dissolved molecular Au(III) precursors. This method can be accomplished in the absence of surfactant and completed in a one single step, but it does not allow a simple control of the final morphology of the built heterostructures.

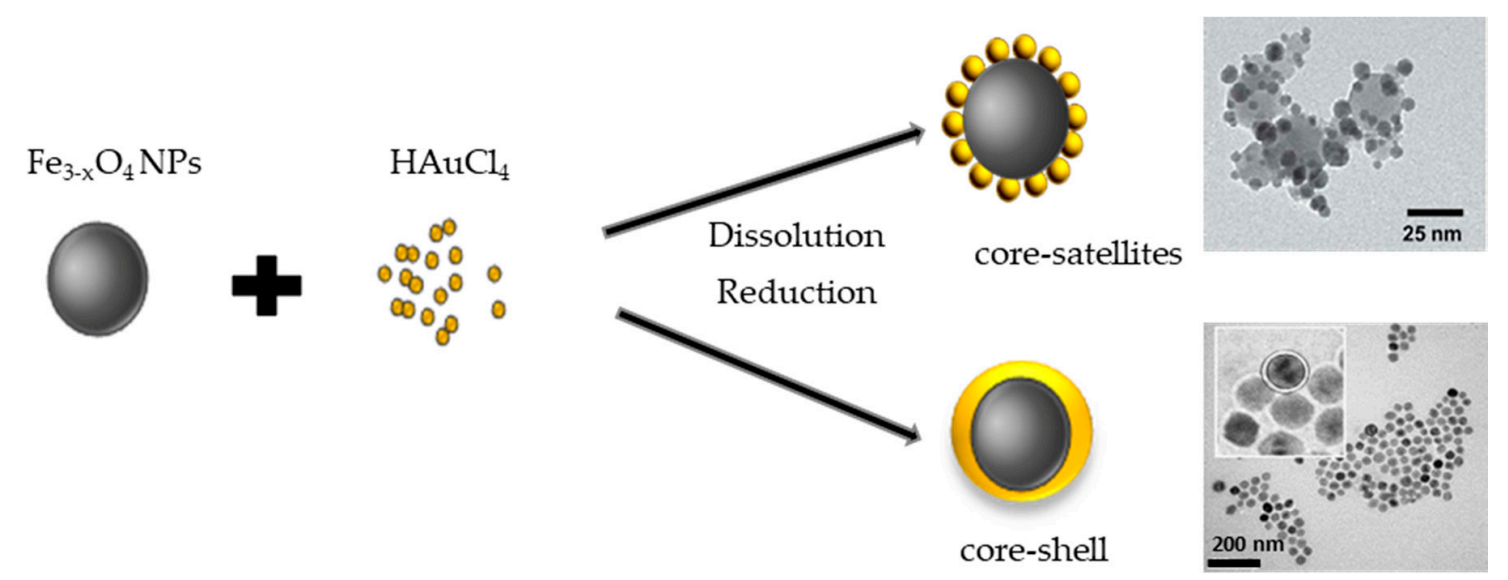

Figure 6. Schematic view of the formation of core-satellites. Reproduced with permission from [53]. Elsevier, 2009, and core-shell spherical structures via the so-called one step route. Reproduced with permission from [54]. John Wiley and Sons, 2015.

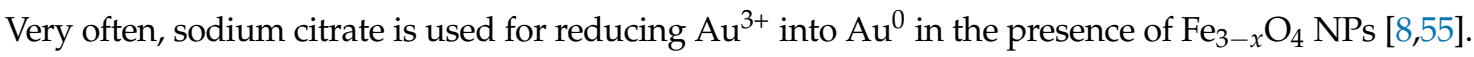
In practice, the surface of $\mathrm{Fe}_{3-x} \mathrm{O}_{4}$ NPs was first modified by sodium citrate to improve their stabilization in water. Au atoms were deposited onto $\mathrm{Fe}_{3-x} \mathrm{O}_{4}$ surface through the reduction of chloroauric acid at the boiling temperature of the reaction solution [56]. Other reducing agents such as DMF [53], $\mathrm{NaBH}_{4}$ [57], hydroxylamine $\left(\mathrm{NH}_{2} \mathrm{OH}\right)$ [58] were also successfully used for the reaction. The thickness of $\mathrm{Au}$ shell was then controlled by changing the ratio between $\mathrm{Fe}_{3-x} \mathrm{O}_{4} \mathrm{NPs}$ and Au precursors.

To produce FANSs with anisotropic in shape Au satellites or shell, the previously described processing routes must be adapted, assuming that the spherical geometry corresponds obviously to the lowest energy shape. Non-spherical morphologies tend to become round with time, to reach the thermodynamical stability. Usually, non-spherical FANSs were produced by controlling experimental parameters like the reducing agent nature, the temperature and time reaction, the nature of gold and/or iron precursors, among others. This control must ensure an anisotropic Au growth onto an anisotropic in shape $\mathrm{Fe}_{3-x} \mathrm{O}_{4}$ core, while preserving the starting morphology, or induce an anisotropic Au growth onto an isotropic in shape $\mathrm{Fe}_{3-x} \mathrm{O}_{4}$ core, leading to a final anisotropic morphology. For example, $\mathrm{Fe}_{3-x} \mathrm{O}_{4}$ nanocubes were functionalized by the positively charged polypeptide, poly-L-histidine (PLH), through charge-charge interactions [59]. The positively charged surface supports $\mathrm{AuCl}_{4}{ }^{-}$ions adsorption and then their subsequent reduction by $\mathrm{NaBH}_{4} \cdot \mathrm{Fe}_{3-x} \mathrm{O}_{4}$, surface modified by imidazole groups, was also able to bind electrostatically to $\mathrm{Au}(\mathrm{III})$ ions, leading to a high $\mathrm{Au}^{\mathrm{III}}$-surface packing density. A controlled reduction of these surface ions results into the formation of an ultra-thin Au shell, while preserving the starting cubic iron oxide core morphology (Figure 7). 


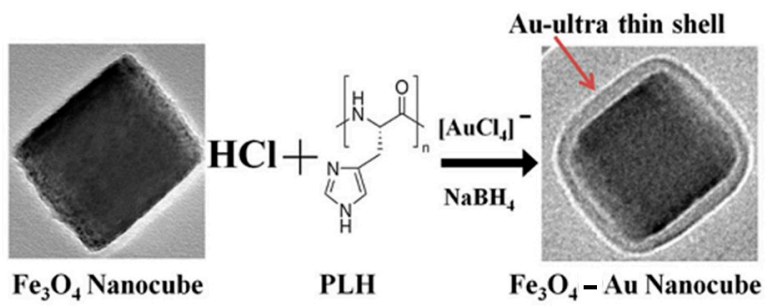

Figure 7. Schematic representation of the synthesis of $\mathrm{Fe}_{3} \mathrm{O}_{4}$-Au core-shell nanocubes, starting from monodisperse hydrophobic magnetic nanocrystals, coated with poly-L-histidine (PLH). The simultaneous addition of gold precursors and reducing reagents leads to the formation of a thin and continuous gold layer on the core nanocubes. Reproduced with permission from [59]. Royal Society of Chemistry, 2013.

Halas' group also reported the synthesis of $\mathrm{Fe}_{3-x} \mathrm{O}_{4}-\mathrm{Au}$ core-shell nanorices, starting from anisotropic in-shape iron oxide core and using the seed-mediated method. $\mathrm{Fe}_{3-x} \mathrm{O}_{4}$ nanorices with a longitudinal diameter of $340 \mathrm{~nm}$ and a transverse diameter of $54 \mathrm{~nm}$ were prepared by heating $\mathrm{FeCl}_{3}$ and potassium dihydrogen phosphate. Their surfaces were then modified by $\mathrm{NH}_{2}$ groups using APTMS. Gold seeds adsorbed on their surface played the role of nucleation sites for the further growth of the gold shell. At the end, Au shells of 10-30 nm in thickness were formed around the $\mathrm{Fe}_{3-x} \mathrm{O}_{4}$ rices, thanks to the reduction of $\mathrm{HAuCl}_{4}$ by formaldehyde in the presence of the seeds. The formation of Au shell preserved the anisotropic shape of iron oxide cores, leading to plasmonic properties in NIR region (Figure 8).

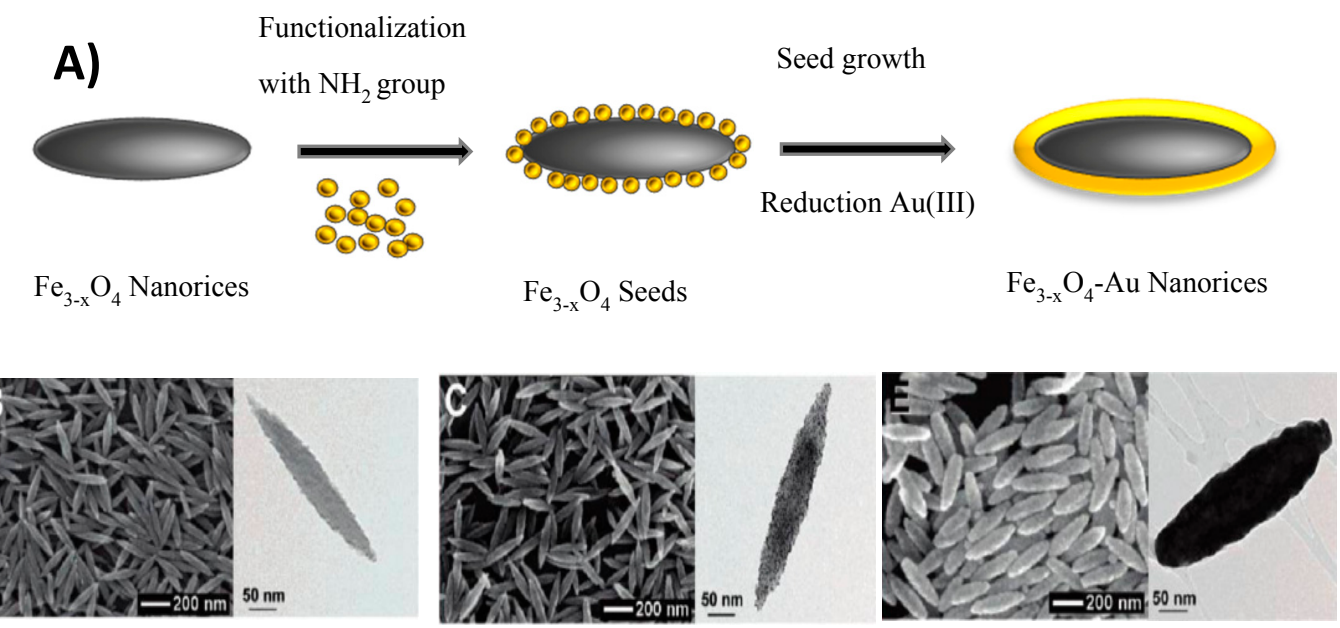

Figure 8. (A) Schematic view of the formation of non-spherical core-shell nanoparticles (NPs) starting from anisotropic in shape iron oxide cores. (B-E) Scanning electron microscopy (SEM) (left) and TEM (right) images of (B) hematite cores; (C) core-satellite particles used as seeds; (E) core-shell nanorice particles. Reproduced with permission from [60]. American Chemical Society, 2006.

Seed-mediated growth is the most common procedure to synthesize anisotropic in shape hetero-nanostructures starting from spherical $\mathrm{Fe}_{3-x} \mathrm{O}_{4}$ cores (Figure 9). In brief, $\mathrm{Fe}_{3-x} \mathrm{O}_{4}-\mathrm{Au}$ core-satellite structures were prepared and used as seeds for the anisotropic growth of the desired gold layer. Au seeds can be formed directly or indirectly on the iron oxide core surface. Alternatively, they can be formed on an intermediate layer of silica sandwiched between the core and Au seeds [61]. Finally, to grow the desired anisotropic in shape Au shell on the seeds, the choice of the reducing agent is of primary importance. It determines the formation rate of $\mathrm{Au}^{0}$ and affects thus the morphology of the final gold coating. Reducing agents such as hydroquinone [62-64] and N,N-dimethylformamide (DMF) [13,14,22] usually produce branched gold shell exhibiting strong absorption in the near infrared region. The addition of silver ions also promotes the growth of anisotropic Au shell [17,61]. 
The presence of silver ions on the gold surface prevents its further growth, favouring irregular shapes. The growth mechanism of anisotropic gold shell is the result of the interplay between the facet binding tendency of the stabilizing agents and the kinetically controlled growth. Besides, dynamic growth happens on all crystal facets, leading to the formation of spherical or near-spherical structures. By optimizing the synthesis conditions, driving kinetic differences in growth rate, atoms can be assembled along specific directions resulting in formation of anisotropic structures. Capping molecules adsorbed onto specific facets offer good conditions to enhance the crystal growth in certain directions and to avoid it in others. The interaction of different gold crystal facets with surfactants could physically drive their anisotropic growth.

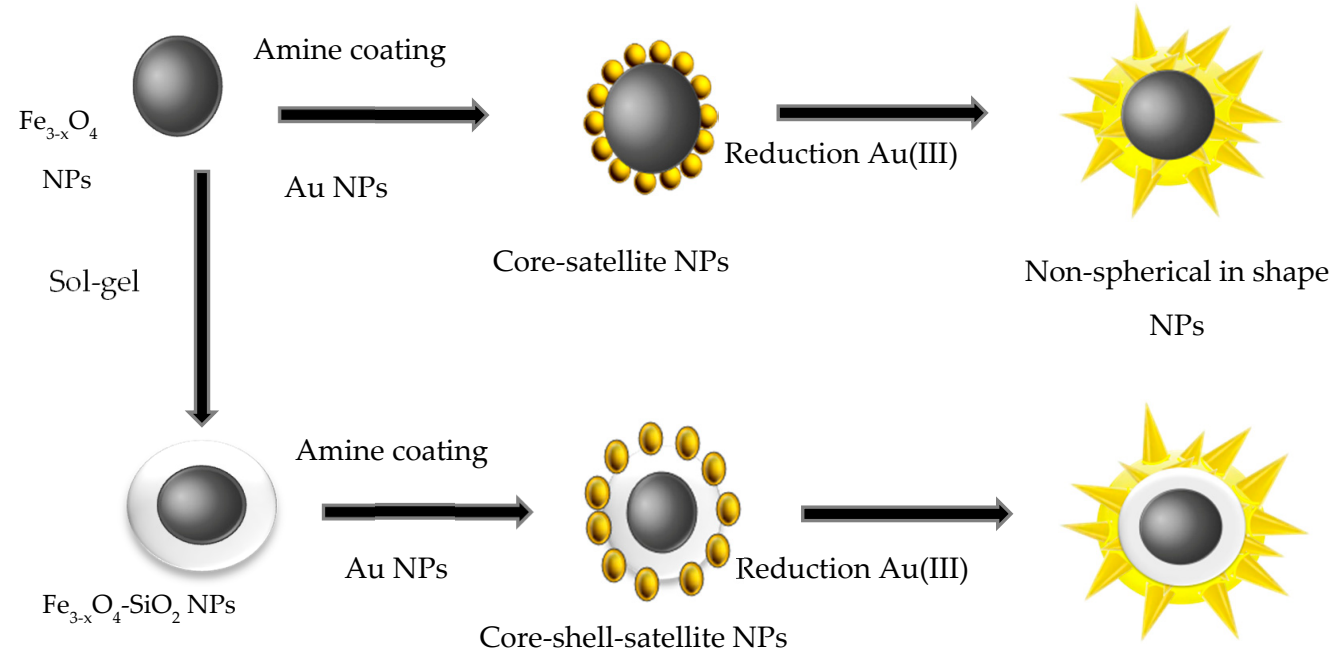

Figure 9. Schematic overview of the formation of non-spherical in shape core-shell structures via seed-mediated method.

Kwizera et al. [48] synthesized 70-250 nm sized $\mathrm{Fe}_{3-x} \mathrm{O}_{4}$-Au heterostructures using a seed-mediated growth method. Newly formed gold atoms were added onto gold-seeded iron oxide octahedrons to lead to a gold shell. The evolution of the geometry of the shell was found to occur after the coalescence of gold seeds, which was achieved by controlling the amount of additive (silver nitrate) and/or specific reducing agent (ascorbic acid) in the growing solution. Experimental results were found to be in good agreement with the data provided by molecular modelling, demonstrating the intimate roles of thermodynamic and kinetic parameters in the shape-controlled synthesis of nanopopcorns or nanostars.

$\mathrm{Li}$ et al. [65] prepared truncated octahedral $\mathrm{Fe}_{3} \mathrm{O}_{4}$ cores coated with a trisoctahedral Au shell. In practice, they attached poly-L-lysine on the surface of the $\mathrm{Fe}_{3} \mathrm{O}_{4}$ cores, to form an intermediate layer, and then submitted the resulting hybrids to a subsequent gold seeded growth, for different reaction times as illustrated in Figure 10.

Concerning the synthesis of the last type of FANS architecture, namely hollow $\mathrm{Fe}_{3-x} \mathrm{O}_{4}-\mathrm{Au}$ core-shell NS, a few numbers of reports exists in the relevant literature. They are usually prepared starting from multifunctional multilayer of $\mathrm{Fe}_{3-x} \mathrm{O}_{4}$-silica-Au [10,49] or $\mathrm{Fe}_{3-x} \mathrm{O}_{4}$-polymer-Au core-shell NSs $[38,44,45]$, and performing etching treatment to remove the intermediate layer of silica or polymer sandwiched between the $\mathrm{Fe}_{3-x} \mathrm{O}_{4}$ core and Au shell to make hollow interior. In practice, iron oxide NPs are functionalized to make their coating by silica or polymer possible. Gold is then prepared by a series of growth of $\mathrm{Au}$ atom onto $\mathrm{Fe}_{3-} \mathrm{O}_{4}$ surface through the reduction of chloroauric acid. After that, the interface between iron oxide core and $\mathrm{Au}$ shell is removed to produce hollow structures. Urries et al. [66] reported $\mathrm{Fe}_{3-x} \mathrm{O}_{4}$-Au hollow structures for magnetic resonance imaging, drug delivery and NIR hyperthermia application. Hollow or semi-hollow interiors have been successfully synthesized and their physico-chemical characteristics have been investigated. 
The resulting NPs maintain the magnetic and optical properties of the iron oxide core and Au shell respectively. By controlling the concentration of the etching agent and the etching time it is possible to remove the interior silica while preserving the inner magnetic cores and the SPR of the Au shell. The hollow interior can be used to store drugs or molecules of interest in the partially etched nanoshells. The final construct has potential as a theranostic platform, combining two therapeutic possibilities (drug delivery and NIR hyperthermia) and imaging capabilities in MRI applications.

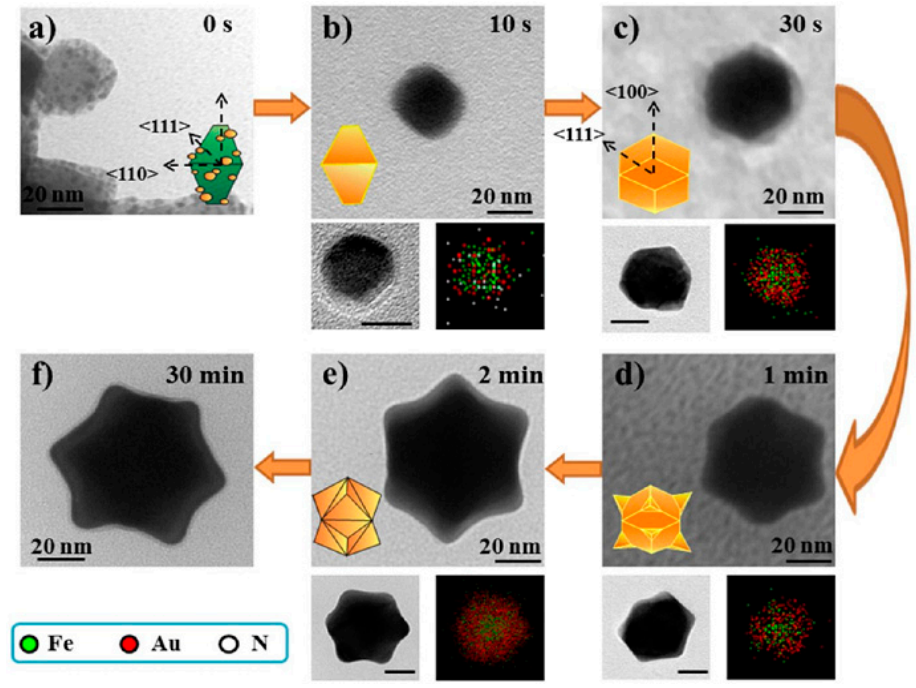

Figure 10. TEM images of $\mathrm{Fe}_{3} \mathrm{O}_{4}$-Au NPs and their elemental analysis (spot-mapping) for different reaction times: (a) 0; (b) $10 \mathrm{~s}$; (c) $30 \mathrm{~s}$; (d) $1 \mathrm{~min}$; (e) $2 \mathrm{~min}$; and (f) $30 \mathrm{~min}$. Iron appears in green, gold in red and nitrogen in white. Reproduced with permission from [65]. American Chemical Society, 2014.

\section{2. $\mathrm{Au}-\mathrm{Fe}_{3-x} \mathrm{O}_{4}$ Nanostructures (AFNSs)}

AFNSs are defined as NPs constituted by a single Au core or multiple Au cores, surrounded by a $\mathrm{Fe}_{3-x} \mathrm{O}_{4}$ coating. The structure of the $\mathrm{Fe}_{3-x} \mathrm{O}_{4}$ coating can be consistent with a single NP, satellites, flower-like structure or smooth thin layer leading to different AFNS architectures. Three main classes were thus defined: Au-Fe ${ }_{3-x} \mathrm{O}_{4}$ dumbbells, $\mathrm{Au}-\mathrm{Fe}_{3-x} \mathrm{O}_{4}$ core-satellites and $\mathrm{Au}-\mathrm{Fe}_{3-x} \mathrm{O}_{4}$ core-shell particles (Figure 11). Compared to FANSs, AFNSs may present interesting magnetic features, in relation (i) with the spin alignment at the interface between the non-magnetic gold matter and the magnetic iron oxide one; and (ii) with the dipolar interactions between the $\mathrm{Fe}_{3-x} \mathrm{O}_{4}$ coating from one AFNS to another. These features are expected to affect the response of AFNSs to an applied magnetic field, which in turn must change their behaviour during MRI or hyperthermia assays, compared to free $\mathrm{Fe}_{3-x} \mathrm{O}_{4}$ nanocrystals.

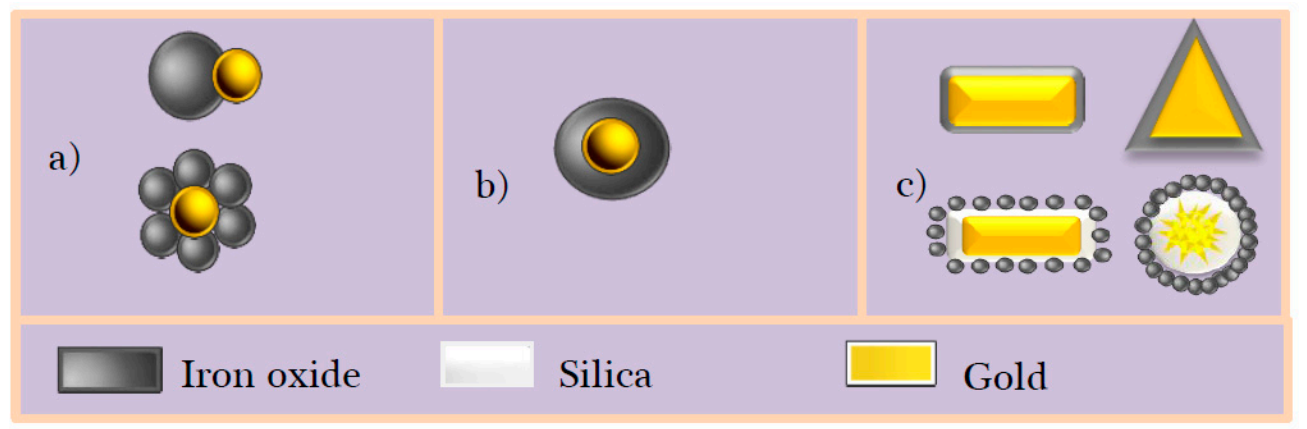

Figure 11. Some structures of Au-Fe ${ }_{3-x} \mathrm{O}_{4}$ Nanostructures (AFNSs): (a) dumbbells and core-satellites; (b) spherical core-shell and (c) non-spherical core-shell. 


\subsubsection{Different Types of AFNSs}

$\mathrm{Au}-\mathrm{Fe}_{3-x} \mathrm{O}_{4}$ Dumbbell Structure

These structures require a single $\mathrm{Au}$ NP and a single $\mathrm{Fe}_{3-x} \mathrm{O}_{4}$ NP linked by an interfacial bond. $\mathrm{Fe}_{3-x} \mathrm{O}_{4}$ may grow on a specific Au crystallographic plane or can be chemically attached on it, through a coupling agent, the other gold surface sites being blocked by ligands with zero affinity to $\mathrm{Fe}_{3-x} \mathrm{O}_{4}$. These structures possess a single plasmonic response. Moreover, their Janus-type bifunctional feature (metal and oxide) makes their surface adapted for different functionalization approaches, facilitating the attachment of various biological molecules, used for in vitro and in vivo biotargeting strategies.

\section{$\mathrm{Au}-\mathrm{Fe}_{3-x} \mathrm{O}_{4}$ Core-Satellite Structure}

In these structures, a single and spherical Au core is surrounded by many $\mathrm{Fe}_{3-x} \mathrm{O}_{4}$ small particles, forming a discontinuous $\mathrm{Fe}_{3-x} \mathrm{O}_{4}$ coating. The main advantage of these NSs is the high surface area provided by the satellite layer, which can be, for instance, useful for chemical catalytic application. Through the integration of two functional components and two surface types, the engineered NSs keep the individual functions of the core and the shell, as well as they impart cooperative properties. Non-spherical Au core, on which small isotropic in shape $\mathrm{Fe}_{3-x} \mathrm{O}_{4}$ particles are distributed as satellites, forms also $\mathrm{Au}-\mathrm{Fe}_{3-x} \mathrm{O}_{4}$ core-satellite structure.

Spherical Au-Fe $e_{3-x} \mathrm{O}_{4}$ Core-Shell Structure

These particles consist mainly of a single Au spherical core, surrounded by a dense and continuous $\mathrm{Fe}_{3-x} \mathrm{O}_{4}$ shell. The surface of the gold core is absolutely inactivated but it keeps its optical properties. The advantage of this structure is to exhibit higher magnetization and higher blocking temperature compared to those of the core-satellite structures.

\section{Non-Spherical Au-Fe ${ }_{3-x} \mathrm{O}_{4}$ Core-Shell Structure}

In this case, the $\mathrm{Au}$ core is still wholly surrounded by $\mathrm{Fe}_{3-x} \mathrm{O}_{4}$ shell; however, its initial morphology is not spherical but looks like more to rods, flowers, stars ... The $\mathrm{Fe}_{3-x} \mathrm{O}_{4}$ coating covers fully its surface. Compared with the spherical $\mathrm{Au}-\mathrm{Fe}_{3-x} \mathrm{O}_{4}$ core-shell structures, the non-spherical ones possess an anisotropic in shape plasmonic core surrounded by a phase presenting a high refractive index and dielectric constant. As a consequence, their optical absorption bands are much more broadened toward the NIR region.

\subsubsection{Synthesis of AFNSs}

The preparation of AFNSs has been mainly developed around the chemical deposition processes and has been often achieved by sequential growths on Au surface. As for FANSs, there are two main processing approaches, the one-pot and the two-steps or modified seed-growth method.

The one pot method consists in mixing all precursors into the same reaction solvent and decomposing $\mathrm{Au}$ and Fe precursors during a heating processing to form the desired $\mathrm{Au}-\mathrm{Fe}_{3-x} \mathrm{O}_{4} \mathrm{NSs}$. Typically, $\mathrm{HAuCl}_{4}$ was introduced in the reaction mixture at the beginning of the reaction [67-71] or during the heating step. Yu et al. [72] injected a solution of $\mathrm{Au}(\mathrm{III})$ chloride in toluene into a fresh $\mathrm{Fe}(\mathrm{CO})_{5}$ organic solution in the presence of oleic acid and oleylamine, and heated the mixture up to $310^{\circ} \mathrm{C}$. The size of the produced Au NPs was controlled by the choice of the injection temperature. An injection of Au precursor at $180{ }^{\circ} \mathrm{C}$, provided $6 \mathrm{~nm}$ and almost spherical sized Au particles, while an injection at $120^{\circ} \mathrm{C}$ resulted in $3 \mathrm{~nm}$ sized Au ones. Sheng et al. [69] also fabricated $\mathrm{Au}-\mathrm{Fe}_{3} \mathrm{O}_{4}$ dumbbell NSs based on epitaxial growth of $\mathrm{Fe}_{3} \mathrm{O}_{4}$ onto $\mathrm{Au}$, but they proceeded almost equivalently. They first formed $\mathrm{Au}$ particles at $140{ }^{\circ} \mathrm{C}$ by adding $\mathrm{HAuCl}_{4}$ into a solution containing oleic acid, oleylamine, 1,2-hexadecanediol and $\mathrm{Fe}(\mathrm{CO})_{5}$. Then, they increased the reaction temperature at a higher temperature to decompose $\mathrm{Fe}(\mathrm{CO})_{5}$. The formed Fe-based solutes started to grow on Au surface, 
leading to $\mathrm{Au}-\mathrm{Fe}_{3} \mathrm{O}_{4}$ dumbbells with a size varying between 5 and $12 \mathrm{~nm}$, just by adjusting the precursor ratio between $\mathrm{Fe}(\mathrm{CO})_{5}$ and $\mathrm{HAuCl}_{4}$ (Figure 12).

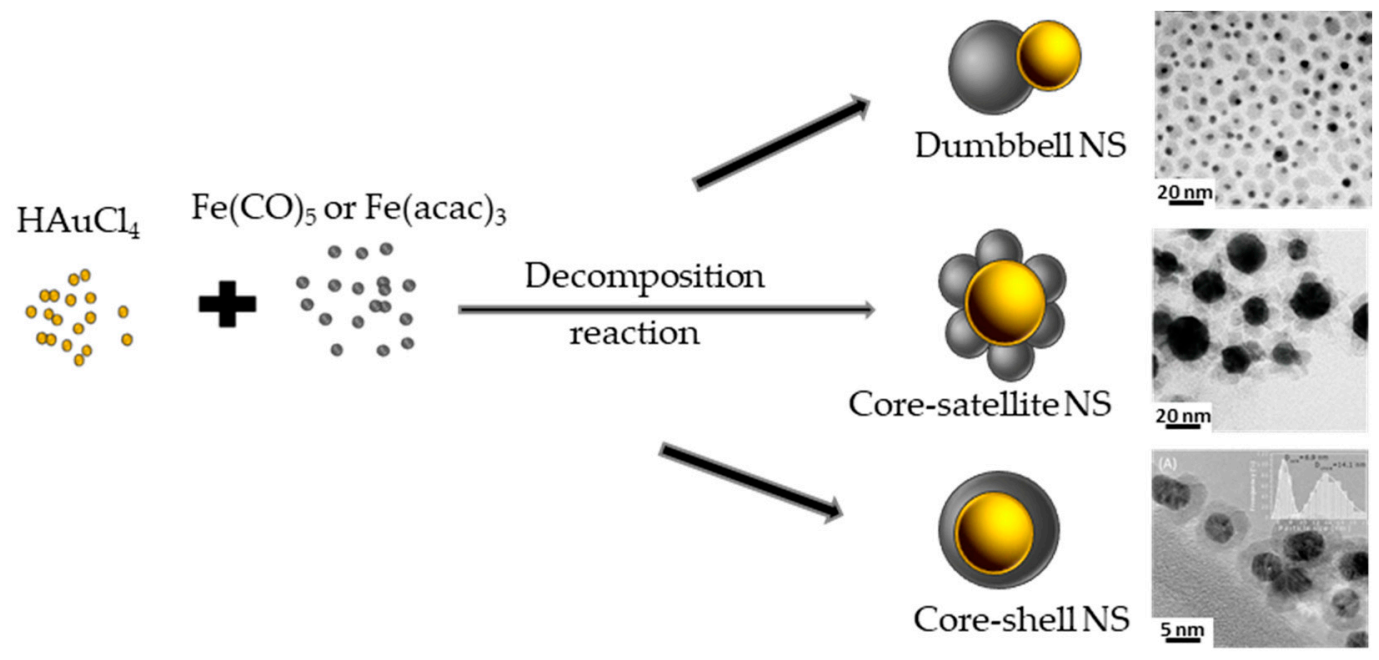

Figure 12. Schematic representation of the one-pot formation of $\mathrm{Au}-\mathrm{Fe}_{3} \mathrm{O}_{4}$ dumbbell, core-satellite core-shell NSs. Representative TEM image of such NSs, reproduced with permission from [69]. Elsevier, 2012, reproduced with permission from [73]. Elsevier, 2016 and reproduced with permission from [74], are given for illustration.

$\mathrm{Au}-\mathrm{Fe}_{3} \mathrm{O}_{4}$ core-satellite NSs were also prepared using the one-pot method, mixing $\mathrm{HAuCl}_{4}$ and $\mathrm{Fe}(\mathrm{acac})_{3}$ in triethyleneglycol (TREG) solvent [11]. TREG played the role of the solvent, reducing agent and capping ligand. The resulting NSs consisted of $80 \mathrm{~nm}$ sized almost isotropic in shape Au core decorated with very small iron oxide particles.

Felix et al. [74] reported the preparation of spherical $\mathrm{Au}-\mathrm{Fe}_{3} \mathrm{O}_{4}$ core-shell NSs using thermal decomposition method. They mixed both ferric acetylacetonate and auric acetate salts in 1-octadecene and 1,2-hexadecanediol in presence of oleylamine and oleic acid surfactants. They heated the reaction medium first up to $120^{\circ} \mathrm{C}$ (for $30 \mathrm{~min}$ ) and then up to $260^{\circ} \mathrm{C}$ to produce the desired microstructure, made of a gold core of $7 \mathrm{~nm}$ in diameter and a magnetite shell of $3.5 \mathrm{~nm}$ in thickness.

The two-steps method, called also modified seeded-growth, is like the seeding growth described previously for FANSs. In this approach, pre-synthesized Au NPs were used as seeds and were introduced into the reaction mixture, containing iron precursors. The growth of $\mathrm{Fe}_{3-x} \mathrm{O}_{4}$ onto $\mathrm{Au}$ surfaces occurred after the thermal decomposition of the iron precursors [69,75-77]. The growth of $\mathrm{Fe}_{3-x} \mathrm{O}_{4}$ depends on many parameters including the nature and the concentration of the iron precursor, the nature and concentration of the surfactants, the solvent polarity, the seed-to-precursor ratio, the temperature rate, the time for each heating plateau, etc. The polarity of solvents is a key parameter [78] since in a non-polar solvent, Au NPs are more negatively charged, preventing iron oxide nucleation and/or growth on their surface, after iron precursor, mainly $\mathrm{Fe}(\mathrm{CO})_{5}$, decomposition. As a result, a single site nucleation was obtained per Au particle to form dumbbell NSs. In polar solvent, the total negative charge of Au NPs decreases, permitting a multiple site nucleation of $\mathrm{Fe}_{3-x} \mathrm{O}_{4}$ on their surface and leading thus to the formation of core-shell structures (Figure 13).

Fantechi et al. [78] synthesized well-defined AFNSs starting from preformed Au seeds of $10 \mathrm{~nm}$ in diameter. By varying the nature of the iron precursor, namely $\mathrm{Fe}(\mathrm{CO})_{5}$ or $\mathrm{Fe}(\mathrm{acac})_{3}$, they observed that the latter is much more sensitive to the variation of the synthesis parameters than the former. So, its thermal decomposition may lead to both heterogeneous and homogeneous $\mathrm{Fe}_{3} \mathrm{O}_{4}$ nucleation and growth, depending on the reaction temperature and the solvent nature. Jiang et al. [76] prepared successfully $\mathrm{Au}-\mathrm{Fe}_{3} \mathrm{O}_{4}$ dumbbells through the sequential decomposition of $\mathrm{Fe}(\mathrm{CO})_{5}$ in the presence of $\mathrm{Au}$ cores of various sizes $(2.5,4,7$ and $10 \mathrm{~nm})$. They showed that the final morphology of the produced 
AFNSs can be controlled just by varying the gold seed size. Lin et al. [79] obtained the same results, using similar operating conditions (Figure 14).

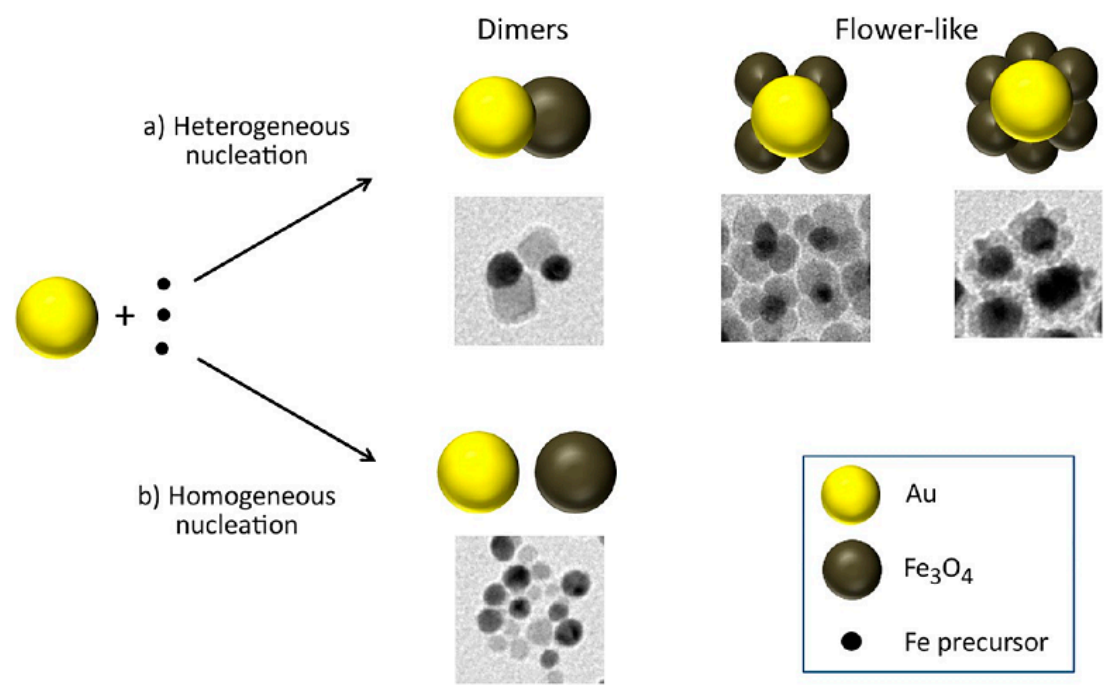

Figure 13. Schematic representation of the possible pathways of the seeded-growth reaction, starting from a mixture of Au nanocystals and molecules of iron precursor. (a) Heterogeneous nucleation of iron oxide, with the formation of either dimers or flower; (b) Homogeneous nucleation of iron oxide, with the consequent formation of isolated iron oxide particles. Reproduced with permission from [78]. American Chemical Society, 2017.
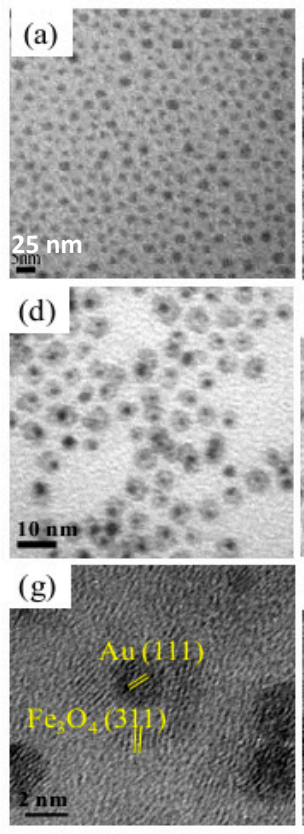
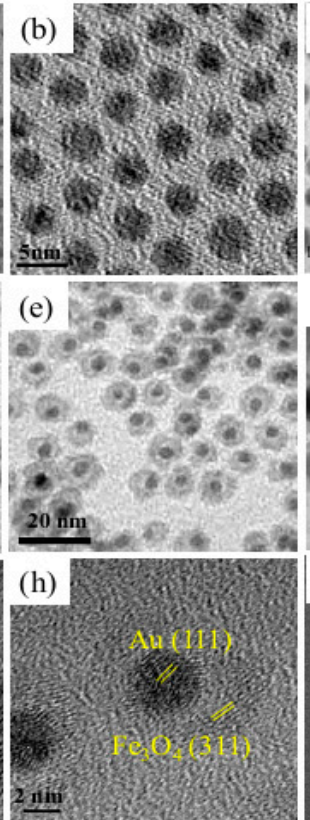
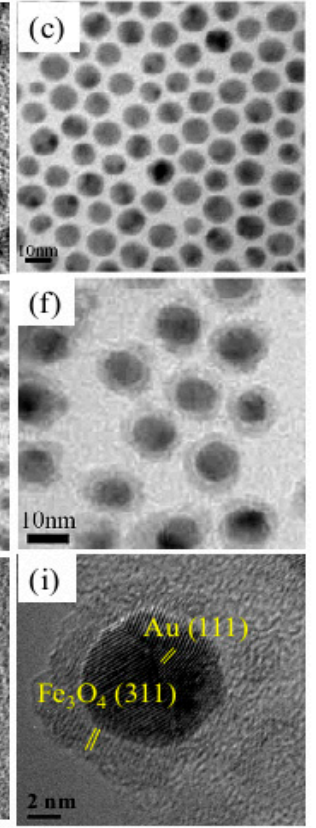

Figure 14. TEM images of Au NPs of (a) 2.5; (b) 4 and (c) $10 \mathrm{~nm}$ and the corresponding $\mathrm{Au}-\mathrm{Fe}_{3} \mathrm{O}_{4}$ yolk-shell NSs starting from (d) 2.5; (e) 4 and (f) $10 \mathrm{~nm}$ sized Au cores. High resolution micrographs of $\mathrm{Au}-\mathrm{Fe}_{3} \mathrm{O}_{4}$ yolk-shell NSs prepared starting from Au cores of (g) 2.5; (h) 4 and (i) $10 \mathrm{~nm}$ in size. Reproduced with permission from [79]. American Chemical Society, 2017.

Non-spherical Au- $\mathrm{Fe}_{3-x} \mathrm{O}_{4}$ core-shell NSs have been also produced by one pot method and sequential growth. Most of the published works described the preparation of hetero-nanostructures based on anisotropic in shape $\mathrm{Au}$ core. Anisotropic $\mathrm{Fe}_{3-x} \mathrm{O}_{4}$ shells have been rarely reported. The preparation of non-spherical $\mathrm{Au}-\mathrm{Fe}_{3} \mathrm{O}_{4}$ core-satellite NPs by one-pot method has been reported by 
Yu et al. [71]. They consist of gold nanotriangles, of about $280 \mathrm{~nm}$ in diameter, decorated by spherical superparamagnetic iron oxide NPs of $5 \mathrm{~nm}$ in diameter. These nanotriangles exhibited SPR in the NIR region $(800 \mathrm{~nm})$.

Non-spherical $\mathrm{Au}-\mathrm{Fe}_{3-x} \mathrm{O}_{4}$ core-satellite NSs can be assembled through electrostatic interactions, by adsorbing $\mathrm{Fe}_{3-x} \mathrm{O}_{4}$ nanocrystals at the surface of Au rods [80-82]. Uniform and smooth $\mathrm{Fe}_{3-x} \mathrm{O}_{4}$ shell coating was also achieved around Au nanorods, by directly reacting $\mathrm{Fe}(\mathrm{acac})_{3}$ on CTAB capped Au surface in aqueous solution at room temperature [83] (Figure 15). Au nanorods were also coated by silica [84], to enhance their colloidal stability in ethanol, before growing $\mathrm{Fe}_{3-x} \mathrm{O}_{4}$ by thermal decomposition of $\mathrm{Fe}(\mathrm{acac})_{3}$ at $290{ }^{\circ} \mathrm{C}$ (Figure 15). In this case, the intermediate silica layer plays the role of a bridge between the gold and iron oxide crystals. It also preserves the plasmonic feature of $\mathrm{Au}$ particles and makes $\mathrm{Fe}_{3-x} \mathrm{O}_{4}$ uniformly distributed.

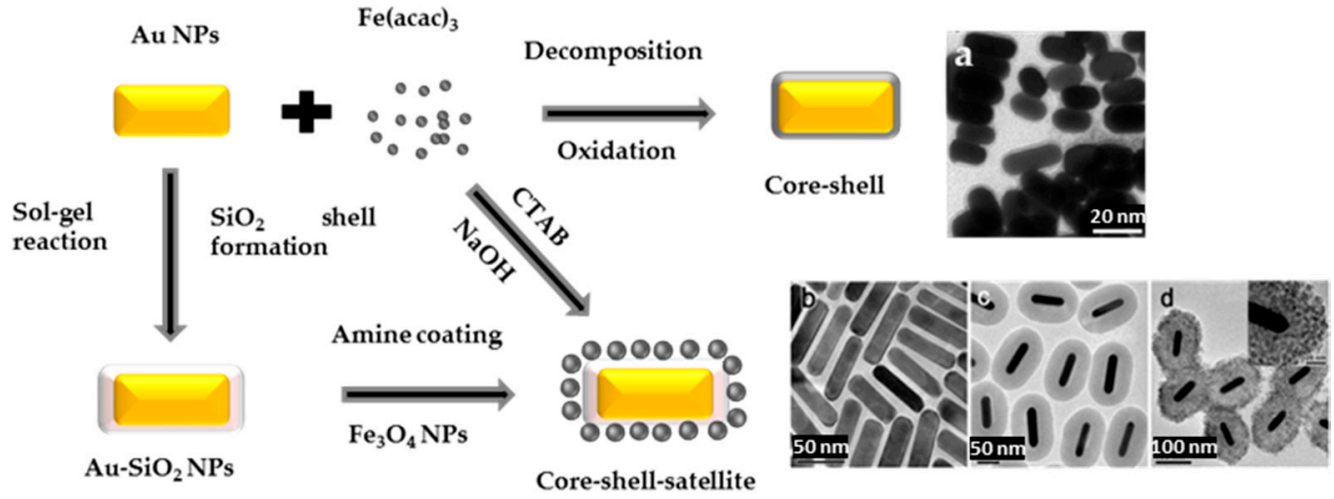

Figure 15. Non-spherical $\mathrm{Au}-\mathrm{Fe}_{3} \mathrm{O}_{4}$ core-satellite NSs starting from Au nanorods. (a) TEM images reproduced with permission from [85]. Springer Nature, 2012. While (b-d) ones reproduced with permission from [84]. American Chemical Society, 2016.

Yang et al. [86] reported the use of polypyrrole (PPy) as a thin mid cohesive layer between Au core and $\mathrm{Fe}_{3-x} \mathrm{O}_{4}$ shell (Figure 16), to encapsulate anisotropic in shape gold NPs, like nanorods, nanotriangles and nanostars. Then, many iron oxide nanocrystals were formed on the surface of Au-PPy nanohybrids. The resulting Au-PPy-Fe $\mathrm{F}_{3-x} \mathrm{O}_{4}$ NSs showed excellent NIR photothermal conversion efficiency, biocompatibility, making them particularly appropriated as theranostic agents for magnetic resonance imaging and photothermal therapy.

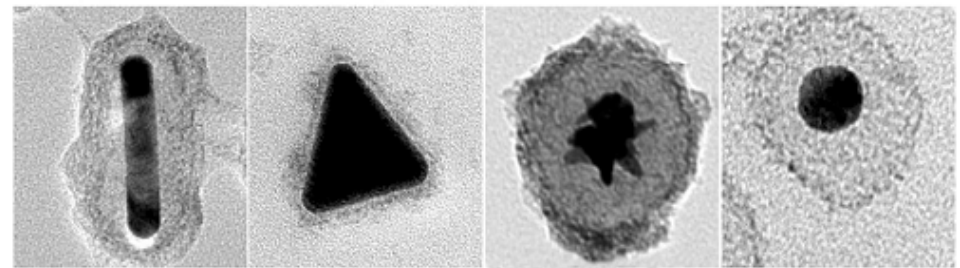

Figure 16. Some non-spherical AFNSs built using a PPy adhesion layer. Reproduced with permission from [86]. Springer Nature, 2016.

\section{Magneto-Plasmonic Properties of FANSs and AFNSs}

\subsection{Optical Properties}

The optical properties of gold NPs are related to the interaction with light of their free conductive electrons on the metal surface. It is known as a surface plasmon resonance (SPR) that causes enhanced absorption and scattering intensities at the plasmon resonance wavelength. The intensity and position of SPR can be controlled by the size, the shape and the dielectric constant of the surrounding medium. SPR is slightly red-shift with increasing of size (Figure 17). 
(a)

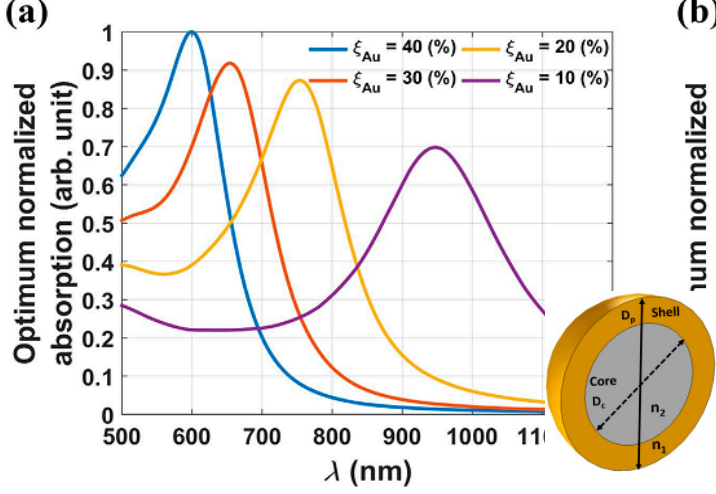

(b)

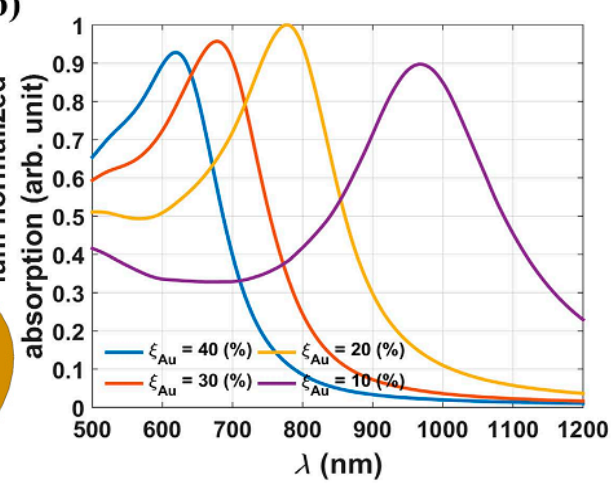

Figure 17. Parametric analysis of optimum normalized absorption vs. $\lambda$ for two different sized $\mathrm{Fe}_{3} \mathrm{O}_{4} @ \mathrm{Au}$ NPS with various shell-to-radius ratios $\xi_{\mathrm{Au}}(\mathbf{a}) \mathrm{D}_{\mathrm{p}}=60 \mathrm{~nm},(\mathbf{b}) \mathrm{D}_{\mathrm{p}}=100 \mathrm{~nm}$. Reproduced with permission from [87].

Mie theory was used to predict the optical spectra of core-shell structured FANSs as a function of their chemical composition, size and shape. It is important to optimize the optical absorption for a large panel of bio-applications. Applying Mie theory, the optical spectra of such hetero-structures were calculated for two different particle sizes, 60 and $100 \mathrm{~nm}$, and various ratios between the shell thickness and the core radius, $10 \%, 20 \%, 30 \%$, and $40 \%$. The obtained spectra showed that the plasmonic absorption band is red-shifted as the ratio decreased [87]. This feature was confirmed experimentally by Canet-Ferrer et al. [88], who evidenced that the extinction spectra of $\mathrm{Fe}_{3} \mathrm{O}_{4}$-Au core-shell NSs of $5 \mathrm{~nm}$ in diameter, exhibited the highest absorption wavelength (around $700 \mathrm{~nm}$ ) when the gold thickness was the thinnest (about $1 \mathrm{~nm}$ ).

Theoretically, to obtain spherical core-shell structured FANSs with a plasmonic absorption over $800 \mathrm{~nm}$, the core needs to be larger than $100 \mathrm{~nm}$ for a shell thickness of about $5 \mathrm{~nm}$.

Another way to shift the plasmonic absorption toward NIR region is to change the NS shape. For example, star-shaped core-satellite structured FANSs exhibit an absorption peak much more red-shifted than spherical ones, due to the sharp tip of gold crystals. These results are well-illustrated in Figure 18 where the UV-Vis-NIR absorption spectra of three kinds of gold-based particles are plotted. The plasmonic absorption of spherical Au NPs was found to be about $520 \mathrm{~nm}$, while that of their nanodumbbell (NDs) and nanodumbbell and star-shaped (called JMNSs) FANS counterparts were red-shifted to $560 \mathrm{~nm}$ and $800 \mathrm{~nm}$, respectively.

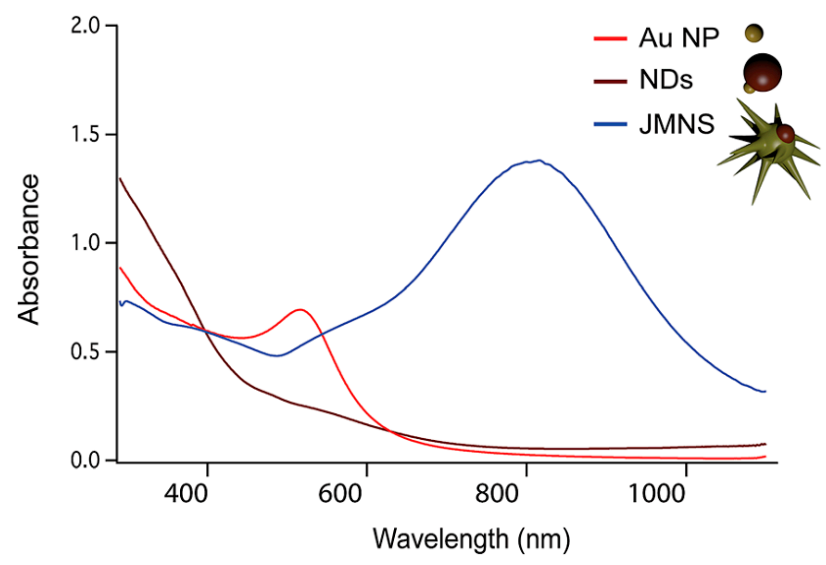

Figure 18. UV-Vis spectra comparing the absorbance of spherical Au NPs (in red), nanodumbbells (in brown) and nanodumbbell and star-shaped (in blue) FANS counterparts. Reproduced with permission from [22]. Royal Society of Chemistry, 2016. 
SPR of AFNSs is also red-shifted as a consequence of the refractive index increase on the gold surrounding media $[69,73,76,89]$. For instance, Umut et al. [55] compared the absorption spectra of $\mathrm{Au}-\mathrm{Fe}_{3} \mathrm{O}_{4}$ dumbbell and core-shell NSs, constituted of an approximatively $8 \mathrm{~nm}$ sized Au core. They observed that, whereas the spectrum of Au single core particles exhibits an absorption at around $520 \mathrm{~nm}$, those of the engineered $\mathrm{Au}-\mathrm{Fe}_{3} \mathrm{O}_{4} \mathrm{NSs}$ exhibited a peak sifted to higher wavelengths (Figure 19). This shift was much more important for the core-shell architecture due to the high refractive index of the iron oxide coating [71].

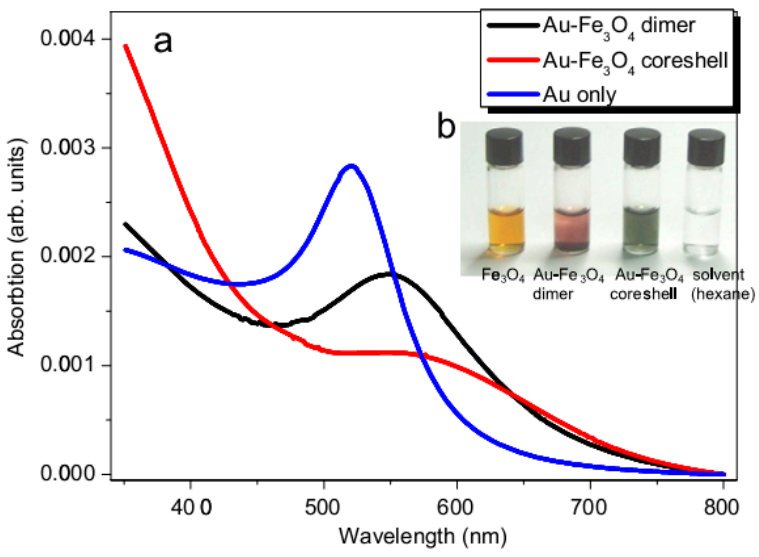

Figure 19. (a) Optical absorption spectra of $\sim 8 \mathrm{~nm}$ sized $\mathrm{Au}, \mathrm{Au}-\mathrm{Fe}_{3} \mathrm{O}_{4}$ dimer and core-shell nanoparticles; and (b) image of $\mathrm{Fe}_{3} \mathrm{O}_{4}$ and $\mathrm{Au}-\mathrm{Fe}_{3} \mathrm{O}_{4} \mathrm{NPs}$ suspensions in hexane. Reproduced with permission from [70]. Elsevier, 2012.

\subsection{Magnetic Properties}

The magnetic properties of both FANSs and AFNSs are mainly driven by those of their magnetic component, depending on their size, composition and structure. For example, if the magnetic core size is below a critical size, the $\mathrm{Fe}_{3-x} \mathrm{O}_{4}$ crystals act as single magnetic domains, with a remanence and coercivity at room temperature. If their size decreases down to another limit, called the superparamagnetic limit, the thermal energy becomes larger than their magnetic anisotropic energy leading to a spontaneous reversal of their magnetization, with zero coercivity and remanence. This behaviour is also characterized by a net irreversibility between the thermal variation of the magnetic susceptibility, when measured in field cooling (FC) conditions and zero field cooling (ZFC) ones. In general, all the investigated gold and iron oxide based-heterostructures in the literature present a superparamagnetic behaviour.

The magnetic properties of FANSs and AFNSs are also significantly dependent on the surface or interface structure of their iron oxide component, its size and its interactions (dipolar or by exchange) with other iron oxide components. Indeed, the interface region between the iron oxide and gold includes broken bonds, which may generate randomness and/or frustration in the exchange interaction between the outer magnetic cations and the inner ones [90]. In some cases, an exchange bias feature can be observed as illustrated in Figure 20, with the appearance of a small shift, along the field axis, of the hysteresis loop recorded in FC conditions by comparison to that recorded in ZFC ones [74]. The iron oxide crystal size reduction leads also to surface iron cation spin disorder, which affects the total magnetic behaviour of the $\mathrm{Fe}_{3-x} \mathrm{O}_{4}$ matter, decreasing the whole magnetization and increasing the total anisotropy. 


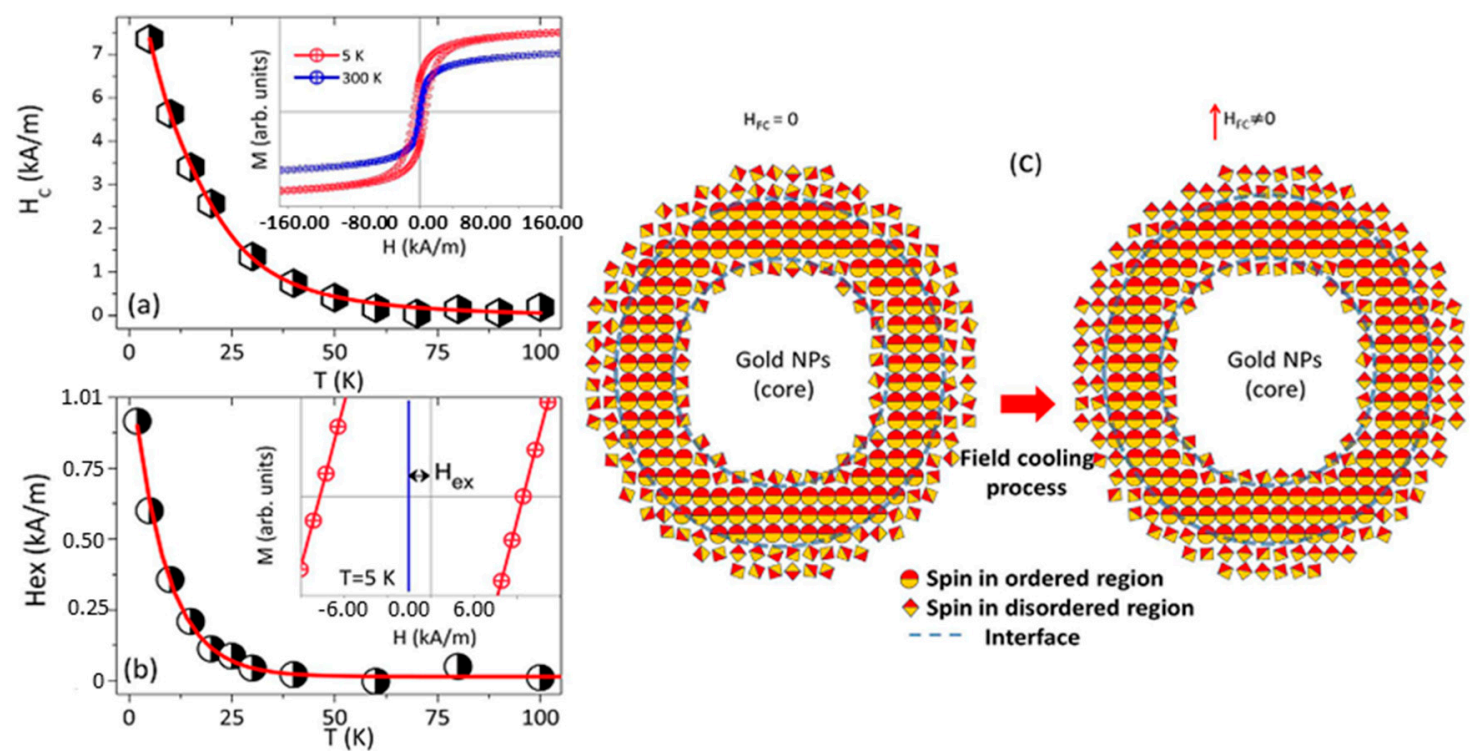

Figure 20. (a) Temperature dependence of the coercive field of the $\mathrm{Au}-\mathrm{Fe}_{3} \mathrm{O}_{4}$ core-shell $\mathrm{NP}$ based fluid sample. The inset shows the hysteresis loops of the investigated AFNSs, as measured at $5 \mathrm{~K}$ and $300 \mathrm{~K}$; (b) The temperature dependence of the exchanged bias field, for field cooling of $2 \mathrm{~T}$. The inset illustrates the magnetization hysteresis loop shift at $5 \mathrm{~K}$; (c) Schematic representations of the different magnetic regions in one particle and the effect produced by the cooling in a magnetic field. Reproduced with permission from [74].

Recently, Felix et al. [74] reported the structural and magnetic properties of AFNSs based on a $6.9 \pm 1.0 \mathrm{~nm}$ in diameter $\mathrm{Au}$ core and a $3.5 \mathrm{~nm}$ in thickness $\mathrm{Fe}_{3} \mathrm{O}_{4}$ shell. They observed that their hetero-nanostructures display a blocked state at temperatures lower than $T_{B}=59 \mathrm{~K}$ and a superparamagnetic one at temperatures higher than $\mathrm{T}_{\mathrm{B}}$. They also evidenced an exchange bias feature when cooling their samples down to $40 \mathrm{~K}$ under an external magnetic field, as a consequence of the interaction between the spins located in the magnetically disordered regions (in the inner and outer surface of the $\mathrm{Fe}_{3} \mathrm{O}_{4}$ shell) and spins located in the ordered region of the $\mathrm{Fe}_{3} \mathrm{O}_{4}$ shell. They clearly measured a non-zero exchange field $\mathrm{H}_{\mathrm{EX}}$, which characterizes the FC-hysteresis loop shift; they also observed a net anisotropy increase compared to bare $\mathrm{Fe}_{3} \mathrm{O}_{4} \mathrm{NPs}$. This increase of the magnetic anisotropy was also reported by other groups. A low temperature coercivity increase as well as a blocking temperature increase were observed by Umut et al. even for dumbbell AFNSs (Figure 21) [70].
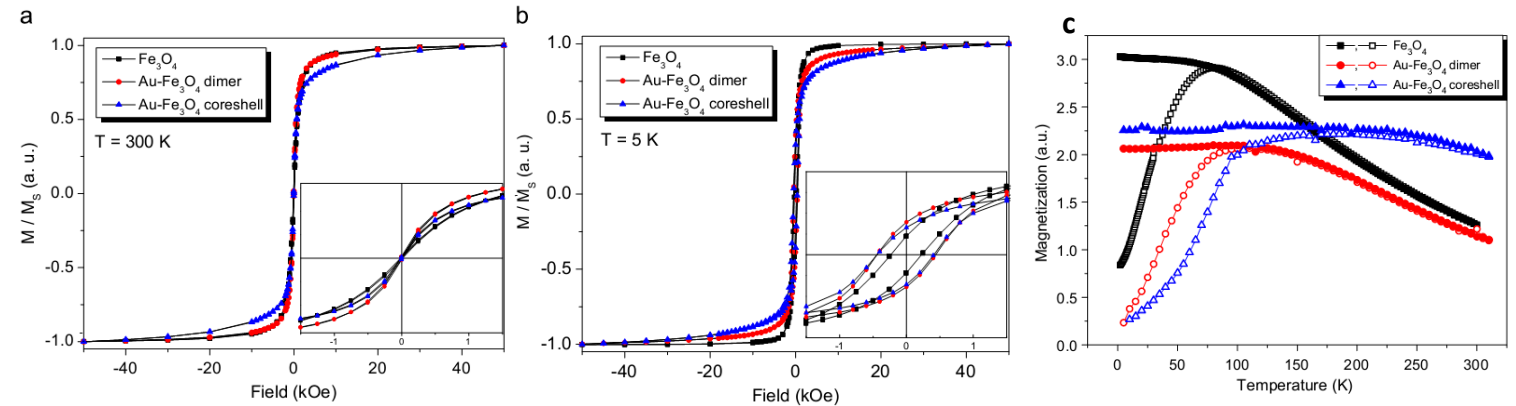

Figure 21. $\mathrm{M} / \mathrm{M}_{\mathrm{S}}$ hysteresis loops measured at $300 \mathrm{~K}(\mathbf{a})$ and $5 \mathrm{~K}(\mathbf{b})$ on powdered $\mathrm{Fe}_{3} \mathrm{O}_{4}$, dimer and core-shell Au- $\mathrm{Fe}_{3} \mathrm{O}_{4}$ NPs. ZFC (hollow symbols) and FC (solid symbols) magnetization measurements of the powder samples for an applied magnetic field $\mathrm{H}=50$ Oe (c). Reproduced with permission from [70]. Elsevier, 2012. 
An important feature of these heterostructures, which is poorly described in the literature, is the modulation of the strength of their mutual dipolar interactions, just by varying their final morphology. Indeed, AFNSs are expected to suffer much more from these interactions than FANSs, since the mutual distance between the magnetic components of two adjacent AFNSs is reduced compared to that between two adjacent FANSs. But in all the cases, these interactions can be significantly reduced when AFNSs (and also FANSs) are dispersed in aqueous media as stable colloids.

Finally replacing in FANSs and AFNSs, the iron oxide single core component by a multicores one, usually allows to increase the magnetization as well as the blocking temperature (polycrystals much more than nanoclusters), which can be particularly useful for magnetic hyperthermia applications [14]. Indeed, the specific absorption rate SAR, which defines the efficiency of a magnetic particle to be used as heating probes under an alternating magnetic field, depends directly on the square of the saturation magnetization [91-93]. The higher the magnetization, the higher the SAR value.

\section{Application of Magneto-Plasmonic Hetero-Nanostructures}

\subsection{Multimodal Imaging}

Magneto-plasmonic nanostructures have been considered for multimodal imaging. MRI has been known as a non-invasive imaging to obtain highly contrasted images of any part of the body by applying external magnetic fields. The non-invasive feature relies on the different water content to distinguish between diseased tissues and healthy ones. Proton nuclear spins align in the direction of the applied DC magnetic field. Under a perpendicular Radio Frequency (RF) pulse, aligned protons are perturbed and return to their original state at the end of the pulse. There are two relaxation processes: the longitudinal relaxation (T1-recovery) and the transverse relaxation (T2-decay), which generate MR images. Superparamagnetic NPs, like iron oxide NPs, enriched in the tissue can provide MR contrast enhancement by shortening mainly T2 relaxation time of its surrounding water protons. They can be thus used as negative contrast agents for T2-weighted MRI.

Optical imaging is also a non-invasive diagnostic method. It is based on the use of light nanosources, which emit enough transparent light to be able to cross body tissues, with wavelengths ranging in the body spectral window, typically in the NIR region. Plasmonic NPs, like gold NPs, exhibit strong unique and tunable optical properties within the visible to NIR spectral region, and can play the role of nanosources. Besides, gold is characterized by a high atomic number, and thus, a high electronic density, making these NPs also suitable to be used in dark field microscopy (DFM), optical coherence tomography (OCT), computed tomography (CT) and photoacoustic (PA) imaging.

Using magneto-plasmonic nanostructures for multimodal imaging, each component possesses featured strengths and weaknesses. The integration of many modalities in a single object is expected to give comprehensive information for diagnostic and treatments of a given disease, like cancers. For example, MRI is a useful imaging tool for the whole-body diffusion-weighted imaging in disease diagnosis. It is a technique with a high spatial resolution, with no tissue penetration limit, but it suffers from low sensitivity. CT is well known as one of the most common imaging modality, with high resolution and detailed 3D visual structure of tissues. However, CT imaging is low sensitive for low density. The integration of MR and CT provides more accurate diagnoses [94]. Hou et al. [95] reported a simple method for synthesizing monodisperse $\mathrm{Fe}_{3} \mathrm{O}_{4}-\mathrm{SiO}_{2}$-Au-PEG FANSs for coupled CT and MR imaging. The as-obtained NSs were composed by a superparamagnetic magnetite inner core, coated with a silica mid-layer and then with an outer gold nanoshell, itself covered by hydrophilic polyethyleneglycol. They exhibited a uniform size distribution with an average diameter of less than $100 \mathrm{~nm}$. Zhu et al. [96] reported the fabrication of $\mathrm{Au}-\mathrm{Fe}_{3} \mathrm{O}_{4}$ AFNSs for in vivo dual CT and MR imaging. They demonstrated that the $\mathrm{Au}-\mathrm{Fe}_{3} \mathrm{O}_{4} \mathrm{NSs}$ can give detailed structures of targeted organs, through their visualization by $\mathrm{CT}$ and by MRI. For instance, they succeeded to visualize simultaneously the right ventricle and the liver of a rabbit by $\mathrm{CT}$ and MR imaging. Li et al. [97] developed a simple one-pot hydrothermal approach to synthesize $\mathrm{Fe}_{3} \mathrm{O}_{4}$ - $\mathrm{Au}$ core-shell structured FANSs and tested them 
for MR and CT imaging. They evidenced that the produced structures have a relatively high $\mathrm{r}_{2}$ relaxivity $\left(146.07 \mathrm{mM}^{-1} \mathrm{~s}^{-1}\right)$ and a good X-ray attenuation property. So, they successfully used them as in vivo contrast agents for liver magnetic imaging and liver and aorta CT imaging, on a small mammal model (mouse). Wang et al. [98] reported a novel ideal AFNS multimodal contrast agents by assembling gold nanocages, functionalized by thiols, and ultra-small iron oxide nanocrystals for simultaneous $\mathrm{T}_{1}-\mathrm{T}_{2}$ dual MRI and CT contrast imaging. These probes exhibited a small average size, a low aggregation and an excellent biocompatibility. Their Au nanocages provided them a strong X-ray attenuation property for $\mathrm{CT}$ imaging, while their ultra-small $\mathrm{Fe}_{3-x} \mathrm{O}_{4} \mathrm{NPs}$ made them able to give enhanced signal of $\mathrm{T}_{1}$ - and $\mathrm{T}_{2}$-weighted MRI $\left(\mathrm{r}_{1}=6.263 \mathrm{mM}^{-1} \mathrm{~s}^{-1}, \mathrm{r}_{2}=28.117 \mathrm{mM}^{-1} \mathrm{~s}^{-1}\right)$. Moreover, in vitro and in vivo studies revealed that they present a long-term circulation time, renal clearance and outstanding capability of selective accumulation in tumours, which is absolutely required for any valuable exogenous imaging probe.

Compared to spherical AFNSs, those presenting an anisotropic shape, e.g., nanostars, nanorods, etc., are much more pursued for biomedical applications, due to their strong SPR in NIR region. They allow in vivo optical imaging and photothermal therapy without any body limits. Many achievements in the development of multimodal MRI and optical imaging or MRI and photothermal therapy using AFNSs have been reported [17,64,99-101] (Figure 22). Larson et al. [102] reported the use of gold-coated iron oxide NPs for combined molecular specific MRI and optical imaging to help guided-laser therapy of cancer cells. The gold shell exhibits a SPR in the red visible region, which can be useful for optical imaging, and presents a convenient surface for conjugating targeting moieties, while the iron oxide core provides a strong $\mathrm{T}_{2}$ (spin-spin relaxation time) MRI contrast.

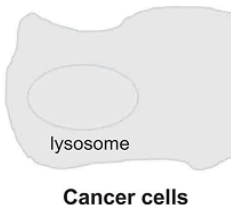

Cancer cells

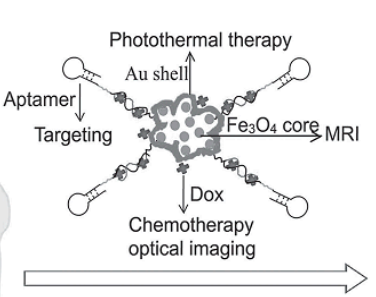

Five-function $\mathrm{Fe}_{3} \mathrm{O}_{4} @$ Au nanorose

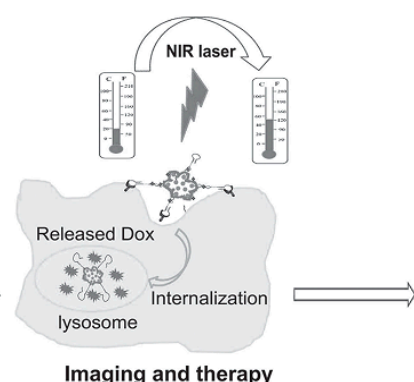

Imaging and therapy

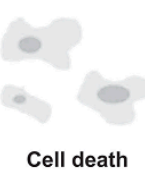

Figure 22. Schematic representation of five-function $\mathrm{Fe}_{3} \mathrm{O}_{4}-\mathrm{Au}$ nanorose for cancer cell targeting, $\mathrm{MR}$ and optical imaging, photothermal and chemotherapy. $\mathrm{Sgc} 8$ aptamers are conjugated to the surface of the nanoroses for targeting of CCRF-CEM malignant cells. Anticancer drug (Doxorubicine) is specifically delivered into cancer cells for chemotherapy. Reproduced with permission from [64]. John Wiley and Sons, 2014.

Li et al. [17] developed hyaluronic acid modified FANSs with a star morphology for MR imaging, thermal imaging and photothermal therapy of tumours. They prepared, first by way of the hydrothermal route, $\mathrm{Fe}_{3} \mathrm{O}_{4}$-Au core-satellite particles and used them as seeds to produce the final nanostar-shaped objects. Further sequential modifications of the resulting particles by polyethyleneimine (PEI) and hyaluronic acid afforded them an excellent colloidal stability, a good biocompatibility, and a targeting specificity to $\mathrm{CD} 44$ receptor-overexpressing cancer cells.

Zhou et al. [8] reported the synthesis of $\mathrm{Fe}_{3} \mathrm{O}_{4}-\mathrm{Au}$ nanostar-shaped core-shell particles for targeting and multimodal imaging of cancer. They evidenced the potential of these NSs for a multimodal MRI, microwave-induced PA and PA imaging. Hu et al. [100] prepared also these anisotropic in shape FANSs but they successfully coated them with folic acid to make them targeted multimodal MR, CT and PA imaging probes. 


\subsection{Multimodal Therapy}

The use of heat has been emerged as a promising tool for cancer therapy. The heating is created from radio frequency, microwaves and ultrasound waves, and used in a specific target region, to perform hyperthermia and treat locally cancers. The cancerous cells being much more sensitive to the temperature increase than healthy ones, such an innovative approach allows selectively damaging and killing at a temperature ranging between $41^{\circ} \mathrm{C}$ and $48^{\circ} \mathrm{C}$, the former instead of the later. The healthy cells can stand alive at so high temperatures. Recently, several novel developments based on the ability of NPs to generate heat under an external stimulus have demonstrated their potential in the treatment of cancers. Typically, the fluctuation of the magnetic moment of magnetic NPs exposed to an alternating magnetic field, transforms the electromagnetic energy into heat. This heat is introduced by the NP magnetic hysteresis loss, Brownian relaxation and Néel relaxation. The amount of generated heat depends on the size and the magnetic properties of NPs. For multi-domain ferri- or ferromagnetic NPs, the heat is only generated by the hysteresis losses. The orientation of the magnetic moments inside the material takes place through the displacements of the magnetic domain walls. For superparamagnetic single domain NPs, the heat is generated by Brownian and Néel relaxations. Brownian relaxations are related to the friction between the NPs and their fluidic media when they are submitted to an oscillating magnetic field. Néel relaxations are associated to the rotation of the magnetic moment with the oscillation of the field within each particle.

Heat energy can be also generated by exposing metallic or dielectric NPs to a laser source, these NPs being able to absorb light, through their plasmonic [103,104] and phonon resonances [105,106], respectively, and to convert it in heat. NIR lasers can cross human tissues with minimal damages. The best material able to absorb in NIR region $(650-1000 \mathrm{~nm})$ for such an application is gold, due to its low cytotoxicity, its biocompatibility and strong optical absorbance in the NIR region. Besides, small gold particles can be aggregated and accumulated in tumours via a passive mechanism and can be used then as local photothermal sources. They can be also cleared out from the body as the therapy is complete, making them particularly valuable for in vivo applications. Very recent works have evidenced the ability of iron oxide to be used for photothermal therapy, exciting its lattice phonons around in the NIR region too, typically around $800 \mathrm{~nm}$. This approach is just emerging and very few works exist in the literature to achieve a complete understood of the involved physical phenomena.

Integrating heating capabilities, magnetic hyperthermia and photothermia in a unique object presents several advantages. For example, magneto-plasmonic nanostructures can be well bio-distributed into the body. They can be accumulated into the malignant tissues, generating heat very locally, when submitted to a light or a magnetic stimulus, preventing damages to healthy cells. Like for the optical imaging application, a fine-control of the morphology of the prepared FANSs and AFNSs is of primary importance, to promote NIR induced heating. Typically, gold nanostars, nanorods, nanoflowers offer strong absorption cross-sections. For magnetic hyperthermia, iron oxide multicore FANSs are much more recommended to reach high heating, due to their high magnetization.

Espinosa et al. [14] combined successfully these two heating modalities using NPs composed of an iron oxide multicore particle coated by a gold shell with tunable plasmonic properties in NIR region. They typically observed an ultrafast tumour temperature increase up to $48^{\circ} \mathrm{C}$, a mandatory condition for therapeutic tumour destruction.

\subsection{Biosensors and SERS Application}

Surface enhanced Raman spectroscopy (SERS) has become one of the most important optical-based analytical techniques for the detection of chemical and biological molecular traces (Table 1). Well-shaped plasmonic particles enhance SERS signal, providing specific fingerprint information for molecular recognition at the single molecule level. With highly sensitive, selective and multiplexed detection capabilities, SERS can be used for in vivo and in vitro studies. Raman signals located on the surface of anisotropic in shape metallic nanostructures such as tips, edges and vertices can be 
enhanced by over 10 orders of magnitude. Therefore, SERS provides information even on traces of the target molecules.

Recently, much effort has been developed to still improve SERS enhancement. One of the most important enhancement factors contributing to the SERS effect is the electromagnetic enhancement which emerges from SPR. The electromagnetic field surrounding plasmonic materials is not uniformly distributed. Its special distribution depends on the structure of the material such as the shape, size, aggregation state, etc. Strong electromagnetic fields could be highly localized in spatially narrow regions, such as nanotips, or a junction between adjacent plasmonic particles (hot spots).

Among various plasmonic materials used for such a purpose, gold remains the most studied, because it can support SPR in the visible region. Its low excitation energy reduces the risk of analyte photobleaching and photodegradation. Its surface is stable toward oxidation. Gold nanomaterials with various size, shape and assembled on substrates have been thus reported.

The integration of an iron oxide component to these gold structures is now receiving a great attention. In one hand, the dielectric properties of the oxide affect the SPR Au response, and in the other hand its magnetic properties can be used for separation and/or pre-concentration of the analytes before SERS application. FANSs, in majority, and AFNSs, in minority have been thus developed for such a purpose [107-111]. They possess the advantages of convenient binding to biomolecules and easy separation using a magnetic field. They can be used for detection of various biological molecules such as proteins, nucleic acids, antibody, cells, hormones [112]. They can be served as carrier for protein or many enzyme molecules. The conjugates of nanostructures with the antibody can be then collected by a magnetic field and deposited on an adapted substrate to be used as SERS-based sensor [113,114].

In practice, SERS applications require magneto-plasmonic hetero-nanostructures in two configurations: (i) colloidal suspensions and (ii) particles immobilized on a substrate. The preparation of colloidal suspensions for SERS experiments is the simplest approach for a good stability and high SERS performance. SERS measurements are easy to achieve, since the engineered NSs have only to be mixed to the analytical solution. A first spectrum can be recorded on a solution very diluted in target molecules. A second spectrum can be achieved on the sample after having applied an external magnetic field for enriching and separating the analytes from the solution, improving thus the detection limit. A monolayer of NSs at the interface of two non-miscible solutions can also be envisaged for SERS detection [29,42]. For example, a monolayer of FANSs at the hexane-water interface was successfully assembled and an external magnetic field was applied to balance the electrostatic interactions, surface tensions and magnetic forces, leading to the expansion and shrinkage of NS distances. Therefore, SERS measurements can be modulated thanks to the dynamic response of the interparticle spacing [45].

The magnetic field can also be used to immobilize NPs on a solid substrate. In this case, the field induces the formation of aggregated or multi-layered structures and facilitates the cyclic use of the NSs. Graphene and graphene-derived materials, which exhibit excellent electronic properties, are considered as suitable substrates for such an application. Graphene can reduce the SERS background, improving thus the Raman signal to noise ratio. Graphene oxide possesses active oxygen sites and highly negative surface charge, enhancing the absorption of positively charged NSs [37,115]. 
Table 1. FANSs and AFNSs for SERS applications.

\begin{tabular}{|c|c|c|c|c|}
\hline Core Material & Shell Material & Reducing Agent & Application & Ref. \\
\hline $\mathrm{Fe}_{3} \mathrm{O}_{4}-\mathrm{SiO}_{2}-\mathrm{NH}_{2} 175 \mathrm{~nm}$ & $\mathrm{Au} 185 \mathrm{~nm}$ & Formaldehyde & Detection of rhodamine & [10] \\
\hline $\mathrm{Fe}_{3} \mathrm{O}_{4}$-BPEI $380 \mathrm{~nm}$ & $\mathrm{Au} 420 \mathrm{~nm}$ & Electrostatic interaction & Detection of low abundance of cancer cell & [44] \\
\hline $\mathrm{Fe}_{3} \mathrm{O}_{4}$-PEI $40 \pm 2 \mathrm{~nm}$ & $\mathrm{Fe}_{3} \mathrm{O}_{4} @ \mathrm{Au} 140 \pm 5 \mathrm{~nm}$ & $\mathrm{NH}_{2} \mathrm{OH} \cdot \mathrm{HCl}$ & Detection of free PSA & [116] \\
\hline $\mathrm{Fe}_{3} \mathrm{O}_{4} 33 \pm 9 \mathrm{~nm}$ & Star-shaped Au $146 \pm 48 \mathrm{~nm}$ & DMF with PVP & Detection of dye molecule of Astra blue and protein magnetic separation & [13] \\
\hline $\mathrm{Fe}_{3} \mathrm{O}_{4} 16.2 \pm 2.8 \mathrm{~nm}$ & Star-shaped $\mathrm{Au} 80 \mathrm{~nm}$ & DMF with PVP & Detection of crystal violet & [22] \\
\hline $\mathrm{Fe}_{3} \mathrm{O}_{4}$-PEI $15 \mathrm{~nm}$ & Star-shaped Au $248 \pm 36 \mathrm{~nm}$ & $\mathrm{NH}_{2} \mathrm{OH}$ & Detection of bacteria & [21] \\
\hline $\mathrm{Fe}_{3} \mathrm{O}_{4}$-PEI $200 \mathrm{~nm}$ & $\mathrm{Au} 220 \mathrm{~nm}$ & $\mathrm{NH}_{2} \mathrm{OH} \cdot \mathrm{HCl}$ & Detection of free-Prostate specific antigen, MRI, magnetic hyperthermia & [117] \\
\hline $\mathrm{Fe}_{3} \mathrm{O}_{4}-\mathrm{SiO}_{2}-\mathrm{NH}_{2} 126 \pm 15 \mathrm{~nm}$ & Star-shaped Au $160 \pm 10-200 \pm 16 \mathrm{~nm}$ & Formaldehyde; $\mathrm{AgNO}_{3}$ & Detection of cancer-related miRNA & [61] \\
\hline Au $90 \mathrm{~nm}$ & $\mathrm{Fe}_{3-x} \mathrm{O}_{4} 97 \mathrm{~nm}$ & TREG & Analysis of the structure and the chemical composition of the surrounding $\mathrm{Fe}_{3-x} \mathrm{O}_{4}$ shell & [11] \\
\hline
\end{tabular}




\section{Conclusions}

This work provides an overview of the relationships between the synthesis, the structure and the properties of multifunctional magneto-plasmonic nanomaterials, based on sequentially architected iron oxide and gold or reversely gold and iron oxide NSs. It also focuses on their applications in the biomedical field. The combination of magnetic and optical properties of gold and iron oxide offers a great potential for magnetic and optical imaging, hyperthermia and photothermia therapy, SERS detection and so on. Besides, from a materials science point of view, these magneto-plasmonic NSs usually exhibit good biocompatibility and colloidal stability. Their physical and chemical properties can be easily tuned by simply acting on their morphology and surface functionalization, respectively. Various morphologies of multifunctional NSs have already been developed, including spherical and non-spherical core-satellite and core-shell particles, leading to interesting magnetic and optical properties. Anisotropic in shape particles have been obtained by controlling the synthesis parameters. Many synthesis methods were used, from simple "one-pot" to complex "multi-step" ones, from seed-mediated to non-seed-mediated routes, adding or not surfactants etc. All these methods present some advantages and challenges to be solved. The engineered NSs generally present the same magnetic properties than their $\mathrm{Fe}_{3-x} \mathrm{O}_{4}$ component alone, with a decrease of the saturation magnetization because of the mass contribution of Au. They also exhibit SPR feature in a wavelength window ranging from the visible to the NIR spectral region depending on their size and shape. Most of the studies have been focused on anisotropic NSs because they possess the chemical, physical, biological properties that are difficult to achieve by spherical ones, in order to use them in multimodal medical therapy and diagnostic.

Acknowledgments: The authors would like to thank the Ministry of Education and Training of Vietnamese government (The 911 USTH Grant Program), which financially supported part of the study through the grant attributed to TTN.

Conflicts of Interest: The authors declare no conflict of interest.

$\begin{array}{ll}\text { Glossary } & \\ \text { NPs } & \text { nanoparticles } \\ \text { CSNPS } & \text { core-shell nanoparticles } \\ \text { MRI } & \text { magnetic resonance imaging } \\ \text { NIR } & \text { near-infrared region } \\ \text { NSs } & \text { nanostructures } \\ \text { QDs } & \text { quantum dots } \\ \text { DOX } & \text { doxorubicin } \\ \text { FANSs } & \text { Fe }_{3-x} \mathrm{O}_{4} \text {-Au nanostructures } \\ \text { AFNSs } & \text { Au-Fe } 3-x \mathrm{O}_{4} \text { nanostructures } \\ \text { TEM } & \text { transmission electron microscopy } \\ \text { PVP } & \text { polyvynilpyrolidone } \\ \text { PSA } & \text { serum albumin protein } \\ \text { DMF } & N_{\text {, }} \text {-dimethylformamide } \\ \text { APTMS } & \text { 3-aminopropyltrimethoxysilane } \\ \text { miRNA } & \text { micro ribonucleic acid } \\ \text { PEI } & \text { polyethylene imine } \\ \text { SPR } & \text { surface plasmon resonance } \\ \text { NDs } & \text { nanodumbbells } \\ \text { RF } & \text { Radio Frequency } \\ \text { DFM } & \text { dark field microscopy } \\ \text { OCT } & \text { optical coherence tomography } \\ \text { CT } & \text { computed tomography } \\ \text { PA } & \text { photoacoustic } \\ & \end{array}$




$\begin{array}{ll}\text { SERS } & \text { surface enhanced Raman scattering } \\ \text { TREG } & \text { triethyleneglycol } \\ \text { UV-Vis } & \text { ultraviolet-visible } \\ \text { FC } & \text { field cooling } \\ \text { ZFC } & \text { zero field cooling }\end{array}$

\section{References}

1. Yen, S.K.; Padmanabhan, P.; Selvan, S.T. Multifunctional iron oxide nanoparticles for diagnostics, therapy and macromolecule delivery. Theranostics 2013, 3, 986-1003. [CrossRef] [PubMed]

2. Lee, N.; Yoo, D.; Ling, D.; Cho, M.H.; Hyeon, T.; Cheon, J. Iron oxide based nanoparticles for multimodal imaging and magnetoresponsive therapy. Chem. Rev. 2015, 115, 10637-10689. [CrossRef] [PubMed]

3. Revia, R.A.; Zhang, M. Magnetite nanoparticles for cancer diagnosis, treatment, and treatment monitoring: Recent advances. Mater. Today 2016, 19, 157-168. [CrossRef] [PubMed]

4. Ghosh, R.; Pradhan, L.; Devi, Y.P.; Meena, S.; Tewari, R.; Kumar, A.; Sharma, S.; Gajbhiye, N.; Vatsa, R.; Pandey, B.N.; et al. Induction heating studies of $\mathrm{Fe}_{3} \mathrm{O}_{4}$ magnetic nanoparticles capped with oleic acid and polyethylene glycol for hyperthermia. J. Mater. Chem. 2011, 21, 13388-13398. [CrossRef]

5. Araújo-Neto, R.; Silva-Freitas, E.; Carvalho, J.; Pontes, T.; Silva, K.; Damasceno, I.; Egito, E.; Dantas, A.L.; Morales, M.A.; Carriço, A.S. Monodisperse sodium oleate coated magnetite high susceptibility nanoparticles for hyperthermia applications. J. Magn. Magn. Mater. 2014, 364, 72-79. [CrossRef]

6. Múzquiz-Ramos, E.; Guerrero-Chávez, V.; Macías-Martínez, B.; López-Badillo, C.; García-Cerda, L. Synthesis and characterization of maghemite nanoparticles for hyperthermia applications. Ceram. Int. 2015, 41, 397-402. [CrossRef]

7. Parak, W.J.; Osinski, M.; Yamamoto, K.I.; Stover, R.; Murthy, A.; Gourisankar, S.; Nie, G.; Martinez, M.; Truskett, T.; Sokolov, K.; et al. Plasmonic biodegradable gold nanoclusters with high NIR-absorbance for biomedical imaging. Int. Soc. Opt. Photonics 2014, 8955, 89550T. [CrossRef]

8. Zhou, T.; Wu, B.; Xing, D. Bio-modified $\mathrm{Fe}_{3} \mathrm{O}_{4}$ core/Au shell nanoparticles for targeting and multimodal imaging of cancer cells. J. Mater. Chem. 2012, 22, 470-477. [CrossRef]

9. Becker, J.; Trügler, A.; Jakab, A.; Hohenester, U.; Sönnichsen, C. The optimal aspect ratio of gold nanorods for plasmonic bio-sensing. Plasmonics 2010, 5, 161-167. [CrossRef]

10. Li, F.; Yu, Z.; Zhao, L.; Xue, T. Synthesis and application of homogeneous $\mathrm{Fe}_{3} \mathrm{O}_{4}$ core/ $\mathrm{Au}$ shell nanoparticles with strong SERS effect. RSC Adv. 2016, 6, 10352-10357. [CrossRef]

11. Mezni, A.; Balti, I.; Mlayah, A.; Jouini, N.; Smiri, L.S. Hybrid Au-Fe $\mathrm{O}_{4}$ nanoparticles: Plasmonic, surface enhanced raman scattering, and phase transition properties. J. Phys. Chem. C 2013, 117, 16166-16174. [CrossRef]

12. Niu, W.; Chua, Y.A.; Zhang, W.; Huang, H.; Lu, X. Highly symmetric gold nanostars: Crystallographic control and surface-enhanced raman scattering property. J. Am. Chem. Soc. 2015, 137, 10460-10463. [CrossRef] [PubMed]

13. Quaresma, P.; Osório, I.; Dória, G.; Carvalho, P.A.; Pereira, A.; Langer, J.; Araújo, J.P.; Pastoriza-Santos, I.; Liz-Marzán, L.M.; Franco, R.; et al. Star-shaped magnetite@gold nanoparticles for protein magnetic separation and SERS detection. RSC Adv. 2014, 4, 3690-3698. [CrossRef]

14. Espinosa, A.; Bugnet, M.; Radtke, G.; Neveu, S.; Botton, G.A.; Wilhelm, C.; Abou-Hassan, A. Can magneto-plasmonic nanohybrids efficiently combine photothermia with magnetic hyperthermia? Nanoscale 2015, 7, 18872-18877. [CrossRef] [PubMed]

15. Gao, Y.; Li, Y.; Chen, J.; Zhu, S.; Liu, X.; Zhou, L.; Shi, P.; Niu, D.; Gu, J.; Shi, J. Multifunctional gold nanostar-based nanocomposite: Synthesis and application for noninvasive MR-SERS imaging-guided photothermal ablation. Biomaterials 2015, 60, 31-41. [CrossRef] [PubMed]

16. Jihye Choi, J.Y.; Jang, E.; Suh, J.; Huh, Y.; Lee, K.; Haam, S. Gold nanostructures as photothermal therapy agent for cancer. Anti-Cancer Agents Med. Chem. 2011, 11, 953-964. [CrossRef]

17. Li, J.; Hu, Y.; Yang, J.; Wei, P.; Sun, W.; Shen, M.; Zhang, G.; Shi, X. Hyaluronic acid-modified $\mathrm{Fe}_{3} \mathrm{O}_{4} / \mathrm{Au}$ core/shell nanostars for multimodal imaging and photothermal therapy of tumours. Biomaterials 2015, 38, 10-21. [CrossRef] [PubMed] 
18. Fan, Z.; Shelton, M.; Singh, A.K.; Senapati, D.; Khan, S.A.; Ray, P.C. Multifunctional plasmonic shell-magnetic core nanoparticles for targeted diagnostics, isolation, and photothermal destruction of tumour cells. ACS Nano 2012, 6, 1065-1073. [CrossRef] [PubMed]

19. Ravichandran, M.; Oza, G.; Velumani, S.; Ramirez, J.T.; Garcia-Sierra, F.; Andrade, N.B.; Vera, A.; Leija, L.; Garza-Navarro, M.A. Plasmonic/magnetic multifunctional nanoplatform for cancer theranostics. Sci. Rep. 2016, 6, 34874. [CrossRef] [PubMed]

20. Wang, L.; Meng, D.; Hao, Y.; Hu, Y.; Niu, M.; Zheng, C.; Yanyan, Y.; Li, D.; Zhang, P.; Chang, J.; et al. A gold nanostar based multi-functional tumour-targeting nanoplatform for tumour theranostic applications. J. Mater. Chem. B 2016, 4, 5895-5906. [CrossRef]

21. Zhang, L.; Xu, J.; Mi, L.; Gong, H.; Jiang, S.; Yu, Q. Multifunctional magnetic-plasmonic nanoparticles for fast concentration and sensitive detection of bacteria using SERS. Biosens. Bioelectron. 2012, 31, 130-136. [CrossRef] [PubMed]

22. Reguera, J.; Jimenez de Aberasturi, D.; Winckelmans, N.; Langer, J.; Bals, S.; Liz-Marzan, L.M. Synthesis of Janus plasmonic-magnetic, star-sphere nanoparticles, and their application in SERS detection. Faraday Discuss. 2016, 191, 47-59. [CrossRef] [PubMed]

23. Kojima, H.; Mukai, Y.; Yoshikawa, M.; Kamei, K.; Yoshikawa, T.; Morita, M.; Inubushi, T.; Yamamoto, T.A.; Yoshioka, Y.; Okada, N.; et al. Simple PEG conjugation of SPIO via an Au-S bond improves its tumour targeting potency as a novel MR tumour imaging agent. Bioconjug. Chem. 2010, 21, 1026-1031. [CrossRef] [PubMed]

24. Lin, J.; Li, Y.; Li, Y.; Wu, H.; Yu, F.; Zhou, S.; Xie, L.; Luo, F.; Lin, C.; Hou, Z. Drug/dye-loaded, multifunctional PEG-chitosan-iron oxide nanocomposites for methotraxate synergistically self-targeted cancer therapy and dual model imaging. ACS Appl. Mater. Interfaces 2015, 7, 11908-11920. [CrossRef] [PubMed]

25. Ghorbani, M.; Hamishehkar, H.; Arsalani, N.; Entezami, A.A. Preparation of thermo and pH-responsive polymer@ $\mathrm{Au} / \mathrm{Fe}_{3} \mathrm{O}_{4}$ core/shell nanoparticles as a carrier for delivery of anticancer agent. J. Nanopart. Res. 2015, 17, 305. [CrossRef]

26. Jin, R.; Song, D.; Xiong, H.; Ai, L.; Ma, P.; Sun, Y. Magnetic core/shell $\mathrm{Fe}_{3} \mathrm{O}_{4} / \mathrm{Au}$ nanoparticles for studies of quinolones binding to protein by fluorescence spectroscopy. Luminescence 2016, 31, 499-506. [CrossRef] [PubMed]

27. Chen, F.; Chen, Q.; Fang, S.; Sun, Y.A.; Chen, Z.; Xie, G.; Du, Y. Multifunctional nanocomposites constructed from $\mathrm{Fe}_{3} \mathrm{O}_{4}$-Au nanoparticle cores and a porous silica shell in the solution phase. Dalton Trans. 2011, 40, 10857-10864. [CrossRef] [PubMed]

28. Gao, Q.; Zhao, A.; Guo, H.; Chen, X.; Gan, Z.; Tao, W.; Zhang, M.; Wu, R.; Li, Z. Controlled synthesis of $\mathrm{Au}-\mathrm{Fe}_{3} \mathrm{O}_{4}$ hybrid hollow spheres with excellent SERS activity and catalytic properties. Dalton Trans. 2014, 43, 7998-8006. [CrossRef] [PubMed]

29. Cai, Q.; Hu, F.; Lee, S.-T.; Liao, F.; Li, Y.; Shao, M. Controllable $\mathrm{Fe}_{3} \mathrm{O}_{4} / \mathrm{Au}$ substrate for surface-enhanced infrared absorption spectroscopy. Appl. Phys. Lett. 2015, 106, 23107. [CrossRef]

30. Zhu, Y.; Lei, J.; Tian, Y. Uniform iron oxide hollow spheres for high-performance delivery of insoluble anticancer drugs. Dalton Trans. 2014, 43, 7275-7281. [CrossRef] [PubMed]

31. Deng, H.; Li, X.; Peng, Q.; Wang, X.; Chen, J.; Li, Y. Monodisperse magnetic single-crystal ferrite microspheres. Angew. Chem. 2005, 117, 2842-2845. [CrossRef]

32. Xia, Q.; Fu, S.; Ren, G.; Chai, F.; Jiang, J.; Qu, F. Fabrication of $\mathrm{Fe}_{3} \mathrm{O}_{4} @ \mathrm{Au}$ hollow spheres with recyclable and efficient catalytic properties. New J. Chem. 2016, 40, 818-824. [CrossRef]

33. Xia, Q.; Fu, S.; Ren, G.; Chai, F.; Jiang, J.; Qu, F. Fabrication of magnetic bimetallic $\mathrm{Fe}_{3} \mathrm{O}_{4} @ \mathrm{Au}-\mathrm{Pd}$ hybrid nanoparticles with recyclable and efficient catalytic properties. RSC Adv. 2016, 6, 55248-55256. [CrossRef]

34. Feng, B.; Hong, R.; Wang, L.; Guo, L.; Li, H.; Ding, J.; Zheng, Y.; Wei, D. Synthesis of $\mathrm{Fe}_{3} \mathrm{O}_{4} /$ APTES/PEG diacid functionalized magnetic nanoparticles for MR imaging. Colloids Surf. A Physicochem. Eng. Asp. 2008, 328, 52-59. [CrossRef]

35. Lou, L.; Yu, K.; Zhang, Z.; Huang, R.; Zhu, J.; Wang, Y.; Zhu, Z. Dual-mode protein detection based on $\mathrm{Fe}_{3} \mathrm{O}_{4}$-Au hybrid nanoparticles. Nano Res. 2012, 5, 272-282. [CrossRef]

36. Del Mar Ramos-Tejada, M.; Viota, J.L.; Rudzka, K.; Delgado, A.V. Preparation of multi-functionalized $\mathrm{Fe}_{3} \mathrm{O}_{4}$-Au nanoparticles for medical purposes. Colloids Surf. B Biointerfaces 2015, 128, 1-7. [CrossRef] [PubMed]

37. Ding, G.; Xie, S.; Zhu, Y.; Liu, Y.; Wang, L.; Xu, F. Graphene oxide wrapped $\mathrm{Fe}_{3} \mathrm{O}_{4}$-Au nanohybrid as SERS substrate for aromatic dye detection. Sens. Actuators B Chem. 2015, 221, 1084-1093. [CrossRef] 
38. Ke, F.; Wang, L.; Zhu, J. Multifunctional Au-Fe $\mathrm{O}_{4} @ \mathrm{MOF}$ core-shell nanocomposite catalysts with controllable reactivity and magnetic recyclability. Nanoscale 2015, 7, 1201-1208. [CrossRef] [PubMed]

39. Uribe Madrid, S.I.; Pal, U.; Kang, Y.S.; Kim, J.; Kwon, H.; Kim, J. Fabrication of $\mathrm{Fe}_{3} \mathrm{O}_{4} @ \mathrm{mSiO}_{2}$ core-shell composite nanoparticles for drug delivery applications. Nanoscale Res. Lett. 2015, 10, 217. [CrossRef] [PubMed]

40. Wang, C.; Li, P.; Wang, J.; Rong, Z.; Pang, Y.; Xu, J.; Dong, P.; Xiao, R.; Wang, S. Polyethylenimine-interlayered core-shell-satellite 3D magnetic microspheres as versatile SERS substrates. Nanoscale 2015, 7, 18694-18707. [CrossRef] [PubMed]

41. Wang, C.; Xu, S.; Zhang, K.; Li, M.; Li, Q.; Xiao, R.; Wang, S. Streptomycin-modified $\mathrm{Fe}_{3} \mathrm{O}_{4}-\mathrm{Au} @ \mathrm{Ag}$ core-satellite magnetic nanoparticles as an effective antibacterial agent. J. Mater. Sci. 2016, 52, 1357-1368. [CrossRef]

42. An, P.; Zuo, F.; Wu, Y.P.; Zhang, J.H.; Zheng, Z.H.; Ding, X.B.; Peng, Y.X. Fast synthesis of dopamine-coated $\mathrm{Fe}_{3} \mathrm{O}_{4}$ nanoparticles through ligand-exchange method. Chin. Chem. Lett. 2012, 23, 1099-1102. [CrossRef]

43. Qiu, Y.; Deng, D.; Deng, Q.; Wu, P.; Zhang, H.; Cai, C. Synthesis of magnetic $\mathrm{Fe}_{3} \mathrm{O}_{4}$-Au hybrids for sensitive SERS detection of cancer cells at low abundance. J. Mater. Chem. B 2015, 3, 4487-4495. [CrossRef]

44. Gan, Z.; Zhao, A.; Zhang, M.; Tao, W.; Guo, H.; Gao, Q.; Mao, R.; Liu, E. Controlled synthesis of Au-loaded $\mathrm{Fe}_{3} \mathrm{O}_{4} @ \mathrm{C}$ composite microspheres with superior SERS detection and catalytic degradation abilities for organic dyes. Dalton Trans. 2013, 42, 8597-8605. [CrossRef] [PubMed]

45. Guo, Q.H.; Zhang, C.J.; Wei, C.; Xu, M.M.; Yuan, Y.X.; Gu, R.A.; Yao, J.L. Controlling dynamic SERS hot spots on a monolayer film of $\mathrm{Fe}_{3} \mathrm{O}_{4} @ \mathrm{Au}$ nanoparticles by a magnetic field. Spectrochim. Acta Part A 2016, 152, 336-342. [CrossRef] [PubMed]

46. Caruntu, D.; Cushing, B.L.; Caruntu, G.; O'Connor, C.J. Attachment of gold nanograins onto colloidal magnetite nanocrystals. Chem. Mater. 2005, 17, 3398-3402. [CrossRef]

47. Ye, M.; Wei, Z.; Hu, F.; Wang, J.; Ge, G.; Hu, Z.; Shao, M.; Lee, S.-T.; Liu, J. Fast assembling microarrays of superparamagnetic $\mathrm{Fe}_{3} \mathrm{O}_{4} @ \mathrm{Au}$ nanoparticle clusters as reproducible substrates for surface-enhanced raman scattering. Nanoscale 2015, 7, 13427-13437. [CrossRef] [PubMed]

48. Kwizera, E.A.; Chaffin, E.; Shen, X.; Chen, J.; Zou, Q.; Wu, Z.; Gai, Z.; Bhana, S.; O'Connor, R.; Wang, L. Size-and shape-controlled synthesis and properties of magnetic-plasmonic core-shell nanoparticles. J. Phys. Chem. C 2016, 120, 10530-10546. [CrossRef] [PubMed]

49. Huang, W.C.; Tsai, P.J.; Chen, Y.C. Multifunctional $\mathrm{Fe}_{3} \mathrm{O}_{4} @ \mathrm{Au}$ nanoeggs as photothermal agents for selective killing of nosocomial and antibiotic-resistant bacteria. Small 2009, 5, 51-56. [CrossRef] [PubMed]

50. Levin, C.S.; Hofmann, C.; Ali, T.A.; Kelly, A.T.; Morosan, E.; Nordlander, P.; Whitmire, K.H.; Halas, N.J. Magnetic-plasmonic core-shell nanoparticles. ACS Nano 2009, 3, 1379-1388. [CrossRef] [PubMed]

51. Liu, X.; Zhong, J.; Rao, H.; Lu, Z.; Ge, H.; Chen, B.; Zou, P.; Wang, X.; He, H.; Zeng, X.; et al. Electrochemical dipyridamole sensor based on molecularly imprinted polymer on electrode modified with $\mathrm{Fe}_{3} \mathrm{O}_{4} @ \mathrm{Au}$ /amine-multi-walled carbon nanotubes. J. Solid State Electrochem. 2017, 21, 3071-3082. [CrossRef]

52. Yuan, Y.; Li, S.; Xue, Y.; Liang, J.; Cui, L.; Li, Q.; Zhou, S.; Huang, Y.; Li, G.; Zhao, Y. A Fe ${ }_{3} \mathrm{O}_{4} @ A$ Au-basedpseudohomogeneous electrochemical immunosensor for AFP measurement using AFP antibody-GNPs-HRP as detection probe. Anal. Biochem. 2017, 534, 56-63. [CrossRef] [PubMed]

53. Kamei, K.; Mukai, Y.; Kojima, H.; Yoshikawa, T.; Yoshikawa, M.; Kiyohara, G.; Yamamoto, T.A.; Yoshioka, Y.; Okada, N.; Seino, S.; et al. Direct cell entry of gold/iron-oxide magnetic nanoparticles in adenovirus mediated gene delivery. Biomaterials 2009, 30, 1809-1814. [CrossRef] [PubMed]

54. Yang, D.; Pang, X.; He, Y.; Wang, Y.; Chen, G.; Wang, W.; Lin, Z. Precisely size-tunable magnetic/plasmonic core/shell nanoparticles with controlled optical properties. Angew. Chem. 2015, 54, 12091-12096. [CrossRef] [PubMed]

55. Karamipour, S.; Sadjadi, M.S.; Farhadyar, N. Fabrication and spectroscopic studies of folic acid-conjugated $\mathrm{Fe}_{3} \mathrm{O}_{4} @ \mathrm{Au}$ core-shell for targeted drug delivery application. Spectrochim. Acta Part A 2015, 148, 146-155. [CrossRef] [PubMed]

56. Banerjee, S.; Raja, S.O.; Sardar, M.; Gayathri, N.; Ghosh, B.; Dasgupta, A. Iron oxide nanoparticles coated with gold: Enhanced magnetic moment due to interfacial effects. J. Appl. Phys. 2011, 109, 123902. [CrossRef]

57. Baskakov, A.O.; Solov'eva, A.Y.; Ioni, Y.V.; Starchikov, S.S.; Lyubutin, I.S.; Khodos, I.I.; Avilov, A.S.; Gubin, S.P. Magnetic and interface properties of the core-shell $\mathrm{Fe}_{3} \mathrm{O}_{4} / \mathrm{Au}$ nanocomposites. Appl. Surf. Sci. 2017, 422, 638-644. [CrossRef] 
58. Lyon, J.L.; Fleming, D.A.; Stone, M.B.; Schiffer, P.; Williams, M.E. Synthesis of Fe oxide core/Au shell nanoparticles by iterative hydroxylamine seeding. Nano Lett. 2004, 4, 719-723. [CrossRef]

59. Abdulla-Al-Mamun, M.; Kusumoto, Y.; Zannat, T.; Horie, Y.; Manaka, H. Au-ultrathin functionalized core-shell $\left(\mathrm{Fe}_{3} \mathrm{O}_{4} @ \mathrm{Au}\right)$ monodispersed nanocubes for a combination of magnetic/plasmonic photothermal cancer cell killing. RSC Adv. 2013, 3, 7816-7827. [CrossRef]

60. Wang, H.; Brandl, D.W.; Le, F.; Nordlander, P.; Halas, N.J. Nanorice: A hybrid plasmonic nanostructure. Nano Lett. 2006, 6, 827-832. [CrossRef] [PubMed]

61. Yang, Y.; Jiang, X.; Chao, J.; Song, C.; Liu, B.; Zhu, D.; Sun, Y.; Yang, B.; Zhang, Q.; Chen, Y.; et al. Synthesis of magnetic core-branched $\mathrm{Au}$ shell nanostructures and their application in cancer-related miRNA detection via SERS. Sci. China Mater. 2017, 60, 1129-1144. [CrossRef]

62. Zhou, H.; Choi, S.I.; Zou, F.; Oh, S.; Kim, J.E.; Hwang, D.Y.; Lee, J. Cytotoxicity and gene expression in sarcoma 180 cells in response to spiky magnetoplasmonic supraparticles. ACS Appl. Mater. Interfaces 2014, 6, 19680-19689. [CrossRef] [PubMed]

63. Zhou, H.; Kim, J.-P.; Bahng, J.H.; Kotov, N.A.; Lee, J. Self-assembly mechanism of spiky magnetoplasmonic supraparticles. Adv. Funct. Mater. 2014, 24, 1439-1448. [CrossRef]

64. Li, C.; Chen, T.; Ocsoy, I.; Zhu, G.; Yasun, E.; You, M.; Wu, C.; Zheng, J.; Song, E.; Huang, C.Z.; et al. Gold-coated $\mathrm{Fe}_{3} \mathrm{O}_{4}$ nanoroses with five unique functions for cancer cell targeting, imaging and therapy. Adv. Funct. Mater. 2014, 24, 1772-1780. [CrossRef] [PubMed]

65. Li, W.-P.; Liao, P.-Y.; Su, C.-H.; Yeh, C.-S. Formation of oligonucleotide-gated silica shell-coated $\mathrm{Fe}_{3} \mathrm{O}_{4}-\mathrm{Au}$ core-shell nanotrisoctahedra for magnetically targeted and near-infrared light-responsive theranostic platform. J. Am. Chem. Soc. 2014, 136, 10062-10075. [CrossRef] [PubMed]

66. Urries, I.; Muñoz, C.; Gomez, L.; Marquina, C.; Sebastian, V.; Arruebo, M.; Santamaria, J. Magneto-plasmonic nanoparticles as theranostic platforms for magnetic resonance imaging, drug delivery and NIR hyperthermia applications. Nanoscale 2014, 6, 9230-9240. [CrossRef] [PubMed]

67. Kirui, D.K.; Rey, D.A.; Batt, C.A. Gold hybrid nanoparticles for targeted phototherapy and cancer imaging. Nanotechnology 2010, 21, 105105. [CrossRef] [PubMed]

68. Li, L.; Du, Y.M.; Mak, K.Y.; Leung, C.W.; Pong, P.W.T. Novel hybrid $\mathrm{Au}-\mathrm{Fe}_{3} \mathrm{O}_{4}$ magnetic octahedron-like nanoparticles with tunable size. IEEE Trans. Magn. 2014, 50, 1-5.

69. Sheng, Y.; Xue, J. Synthesis and properties of $\mathrm{Au}-\mathrm{Fe}_{3} \mathrm{O}_{4}$ heterostructured nanoparticles. J. Colloid Interface Sci. 2012, 374, 96-101. [CrossRef] [PubMed]

70. Umut, E.; Pineider, F.; Arosio, P.; Sangregorio, C.; Corti, M.; Tabak, F.; Lascialfari, A.; Ghigna, P. Magnetic, optical and relaxometric properties of organically coated gold-magnetite $\left(\mathrm{Au}-\mathrm{Fe}_{3} \mathrm{O}_{4}\right)$ hybrid nanoparticles for potential use in biomedical applications. J. Magn. Magn. Mater. 2012, 324, 2373-2379. [CrossRef]

71. Yu, S.; Hachtel, J.A.; Chisholm, M.F.; Pantelides, S.T.; Laromaine, A.; Roig, A. Magnetic gold nanotriangles by microwave-assisted polyol synthesis. Nanoscale 2015, 7, 14039-14046. [CrossRef] [PubMed]

72. Yu, H.; Chen, M.; Rice, P.M.; Wang, S.X.; White, R.L.; Sun, S. Dumbbell-like bifunctional Au-Fe ${ }_{3} \mathrm{O}_{4}$ nanoparticles. Nano Lett. 2005, 5, 379-382. [CrossRef] [PubMed]

73. Shen, J.; Yang, Y.; Zhang, Y.; Yang, H.; Zhou, Z.; Yang, S. Functionalized Au-Fe ${ }_{3} \mathrm{O}_{4}$ nanocomposites as a magnetic and colorimetric bimodal sensor for melamine. Sens. Actuators B Chem. 2016, 226, 512-517. [CrossRef]

74. Leon Felix, L.; Coaquira, J.A.; Martinez, M.A.; Goya, G.F.; Mantilla, J.; Sousa, M.H.; Valladares, L.L.; Barnes, C.H.; Morais, P.C. Structural and magnetic properties of core-shell $\mathrm{Au} / \mathrm{Fe}_{3} \mathrm{O}_{4}$ nanoparticles. Sci. Rep. 2017, 7, 41732. [CrossRef] [PubMed]

75. Xu, C.; Wang, B.; Sun, S. Dumbbell-like $\mathrm{Au}-\mathrm{Fe}_{3} \mathrm{O}_{4}$ nanoparticles for target-specific platin delivery. J. Am. Chem. Soc. 2009, 131, 4216-4217. [CrossRef] [PubMed]

76. Jiang, G.; Huang, Y.; Zhang, S.; Zhu, H.; Wu, Z.; Sun, S. Controlled synthesis of Au-Fe heterodimer nanoparticles and their conversion into $\mathrm{Au}-\mathrm{Fe}_{3} \mathrm{O}_{4}$ heterostructured nanoparticles. Nanoscale 2016, 8, 17947-17952. [CrossRef] [PubMed]

77. Xie, J.; Zhang, F.; Aronova, M.; Zhu, L.; Lin, X.; Quan, Q.; Liu, G.; Zhang, G.; Choi, K.-Y.; Kim, K.; et al. Manipulating the power of an additional phase: A flower-like $\mathrm{Au}-\mathrm{Fe}_{3} \mathrm{O}_{4}$ ptical nanosensor for imaging protease expressions in vivo. ACS Nano 2011, 5, 3043-3051. [CrossRef] [PubMed]

78. Fantechi, E.; Roca, A.G.; Sepúlveda, B.; Torruella, P.; Estradé, S.; Peiró, F.; Coy, E.; Jurga, S.; Bastús, N.G.; Nogués, J.; et al. Seeded growth synthesis of $\mathrm{Au}-\mathrm{Fe}_{3} \mathrm{O}_{4}$ heterostructured nanocrystals: Rational design and mechanistic insights. Chem. Mater. 2017, 29, 4022-4035. [CrossRef] 
79. Lin, F.-H.; Doong, R.-A. Catalytic nanoreactors of $\mathrm{Au} @ \mathrm{Fe}_{3} \mathrm{O}_{4}$ yolk-shell nanostructures with various au sizes for efficient nitroarene reduction. J. Phys. Chem. C 2017, 121, 7844-7853. [CrossRef]

80. Cai, W.; Shin, D.-W.; Chen, K.; Gheysens, O.; Cao, Q.; Wang, S.X.; Gambhir, S.S.; Chen, X. Peptide-labeled near-infrared quantum dots for imaging tumor vasculature in living subjects. Nano Lett. 2006, 6, 669-676. [CrossRef] [PubMed]

81. Cheng, R.; Meng, F.; Deng, C.; Klok, H.-A.; Zhong, Z. Dual and multi-stimuli responsive polymeric nanoparticles for programmed site-specific drug delivery. Biomaterials 2013, 34, 3647-3657. [CrossRef] [PubMed]

82. Dhakshinamoorthy, A.; Asiri, A.M.; Garcia, H. Metal organic frameworks as versatile hosts of Au nanoparticles in heterogeneous catalysis. ACS Catal. 2017, 7, 2896-2919. [CrossRef]

83. Ding, H.; Zhang, Y.; Wang, S.; Xu, J.; Xu, S.; Li, G. Au-Fe $\mathrm{O}_{4} @ \mathrm{SiO}_{2}$ core/shell nanoparticles: The silica coating regulations with a single core for different core sizes and shell thicknesses. Chem. Mater. 2012, 24, 4572-4580. [CrossRef]

84. Huang, L.; Ao, L.; Hu, D.; Wang, W.; Sheng, Z.; Su, W. Magneto-plasmonic nanocapsules for multimodal-imaging and magnetically guided combination cancer therapy. Chem. Mater. 2016, 28, 5896-5904. [CrossRef]

85. Tian, Y.; Chen, L.; Zhang, J.; Ma, Z.; Song, C. Bifunctional Au-nanorod@ $\mathrm{Fe}_{3} \mathrm{O}_{4}$ nanocomposites: Synthesis, characterization, and their use as bioprobes. J. Nanopart. Res. 2012, 14, 998. [CrossRef]

86. Yang, Z.; Ding, X.; Jiang, J. Facile synthesis of magnetic-plasmonic nanocomposites as T1 MRI contrast enhancing and photothermal therapeutic agents. Nano Res. 2016, 9, 787-799. [CrossRef]

87. Xue, X.; Sukhotskiy, V.; Furlani, E.P. Optimization of optical absorption of colloids of $\mathrm{SiO}_{2} @ \mathrm{Au}$ and $\mathrm{Fe}_{3} \mathrm{O}_{4} @ \mathrm{Au}$ nanoparticles with constraints. Sci. Rep. 2016, 6, 35911. [CrossRef] [PubMed]

88. Canet-Ferrer, J.; Albella, P.; Ribera, A.; Usagre, J.; Maier, S. Hybrid magnetite-gold nanoparticles as bifunctional magnetic-plasmonic systems: Three representative cases. Nanoscale Horiz. 2017, 2, 205-216. [CrossRef]

89. Lin, F.H.; Doong, R.A. Characterization of interfacially electronic structures of gold-magnetite heterostructures using x-ray absorption spectroscopy. J. Colloid Interface Sci. 2014, 417, 325-332. [CrossRef] [PubMed]

90. Pineider, F.; Fernández, C.D.; Videtta, V.; Carlino, E.; al Hourani, A.; Wilhelm, F.; Rogalev, A.; Cozzoli, P.D.; Ghigna, P.; Sangregorio, C. Spin-polarization transfer in colloidal colloidal magnetic-plasmonic au/iron oxide hetero-nanocrystals. ACS Nano 2013, 7, 857-866. [CrossRef] [PubMed]

91. Hugounenq, P.; Levy, M.; Alloyeau, D.; Lartigue, L.; Dubois, E.; Cabuil, V.R.; Ricolleau, C.; Roux, S.P.; Wilhelm, C.; Gazeau, F.; et al. Iron oxide monocrystalline nanoflowers for highly efficient magnetic hyperthermia. J. Phys. Chem. C 2012, 116, 15702-15712. [CrossRef]

92. Martinez-Boubeta, C.; Simeonidis, K.; Makridis, A.; Angelakeris, M.; Iglesias, O.; Guardia, P.; Cabot, A.; Yedra, L.; Estradé, S.; Peiró, F.; et al. Learning from nature to improve the heat generation of iron-oxide nanoparticles for magnetic hyperthermia applications. Sci. Rep. 2013, 3, 1652. [CrossRef] [PubMed]

93. Ludwig, R.; Stapf, M.; Dutz, S.; Müller, R.; Teichgräber, U.; Hilger, I. Structural properties of magnetic nanoparticles determine their heating behaviour-an estimation of the in vivo heating potential. Nanoscale Res. Lett. 2014, 9, 602. [CrossRef] [PubMed]

94. He, X.; Liu, F.; Liu, L.; Duan, T.; Zhang, H.; Wang, Z. Lectin-conjugated $\mathrm{Fe}_{3} \mathrm{O}_{4} @ \mathrm{Au}$ core@shell nanoparticles as dual mode contrast agents for in vivo detection of tumor. Mol. Pharm. 2014, 11, 738-745. [CrossRef] [PubMed]

95. Hou, X.; Wang, X.; Liu, R.; Zhang, H.; Liu, X.; Zhang, Y. Facile synthesis of multifunctional $\mathrm{Fe}_{3} \mathrm{O}_{4} @ \mathrm{SiO}_{2} @ \mathrm{Au}$ magneto-plasmonic nanoparticles for $\mathrm{mr} / \mathrm{ct}$ dual imaging and photothermal therapy. RSC Adv. 2017, 7, 18844-18850. [CrossRef]

96. Zhu, J.; Lu, Y.; Li, Y.; Jiang, J.; Cheng, L.; Liu, Z.; Guo, L.; Pan, Y.; Gu, H. Synthesis of $\mathrm{Au}^{-\mathrm{Fe}_{3} \mathrm{O}_{4}}$ heterostructured nanoparticles for in vivo computed tomography and magnetic resonance dual model imaging. Nanoscale 2014, 6, 199-202. [CrossRef] [PubMed]

97. Li, J.; Zheng, L.; Cai, H.; Sun, W.; Shen, M.; Zhang, G.; Shi, X. Facile one-pot synthesis of $\mathrm{Fe}_{3} \mathrm{O}_{4} @ \mathrm{Au}$ composite nanoparticles for dual-mode MR/CT imaging applications. ACS Appl. Mater. Interfaces 2013, 5, 10357-10366. [CrossRef] [PubMed]

98. Wang, G.; Gao, W.; Zhang, X.; Mei, X. Au nanocage functionalized with ultra-small $\mathrm{Fe}_{3} \mathrm{O}_{4}$ nanoparticles for targeting T1-T2 dual MRI and CT imaging of tumor. Sci. Rep. 2016, 6, 28258. [CrossRef] [PubMed]

99. Ma, L.L.; Feldman, M.D.; Tam, J.M.; Paranjape, A.S.; Cheruku, K.K.; Larson, T.A.; Tam, J.O.; Ingram, D.R.; Paramita, V.; Villard, J.W.; et al. Small multifunctional nanoclusters for targeted cellular imaging and therapy. ACS Nano 2009, 3, 2686-2696. [CrossRef] [PubMed] 
100. Hu, Y.; Wang, R.; Wang, S.; Ding, L.; Li, J.; Luo, Y.; Wang, X.; Shen, M.; Shi, X. Multifunctional Fe $\mathrm{F}_{4} @ \mathrm{Au}$ core/shell nanostars: A unique platform for multimode imaging and photothermal therapy of tumors. Sci. Rep. 2016, 6, 28325. [CrossRef] [PubMed]

101. Cho, S.-J.; Jarrett, B.R.; Louie, A.Y.; Kauzlarich, S.M. Gold-coated iron nanoparticles: A novel magnetic resonance agent for T1 and T2 weighted imaging. Nanotechnology 2006, 17, 640. [CrossRef]

102. Larson, T.A.; Bankson, J.; Aaron, J.; Sokolov, K. Hybrid plasmonic magnetic nanoparticles as molecular specific agents for MRI/optical imaging and photothermal therapy of cancer cells. Nanotechnology 2007, 18, 325101. [CrossRef]

103. Han, H.S.; Choi, K.Y.; Lee, H.; Lee, M.; An, J.Y.; Shin, S.; Kwon, S.; Lee, D.S.; Park, J.H. Gold-nanoclustered hyaluronan nano-assemblies for photothermally maneuvered photodynamic tumor ablation. ACS Nano 2016, 10, 10858-10868. [CrossRef] [PubMed]

104. Van de Broek, B.; Devoogdt, N.; D’Hollander, A.; Gijs, H.-L.; Jans, K.; Lagae, L.; Muyldermans, S.; Maes, G.; Borghs, G. Specific cell targeting with nanobody conjugated branched gold nanoparticles for photothermal therapy. ACS Nano 2011, 5, 4319-4328. [CrossRef] [PubMed]

105. Guardia, P.; Di Corato, R.; Lartigue, L.; Wilhelm, C.; Espinosa, A.; Garcia-Hernandez, M.; Gazeau, F.; Manna, L.; Pellegrino, T. Water-soluble iron oxide nanocubes with high values of specific absorption rate for cancer cell hyperthermia treatment. ACS Nano 2012, 6, 3080-3091. [CrossRef] [PubMed]

106. Beji, Z.; Hanini, A.; Smiri, L.; Gavard, J.; Kacem, K.; Villain, F.; Greneche, J.-M.; Chau, F.; Ammar, S. Magnetic properties of zn-substituted $\mathrm{MnFe}_{3} \mathrm{O}_{4}$ nanoparticles synthesized in polyol as potential heating agents for hyperthermia. Evaluation of their toxicity on endothelial cells. Chem. Mater. 2010, 22, 5420-5429. [CrossRef]

107. Manera, M.; Colombelli, A.; Rella, R.; Caricato, A.; Cozzoli, P.; Martino, M.; Vasanelli, L. TiO 2 brookite nanostructured thin layer on magneto-optical surface plasmon resonance transductor for gas sensing applications. J. Appl. Phys. 2012, 112, 53524. [CrossRef]

108. Chou, K.-H.; Lin, E.-P.; Chen, T.-C.; Lai, C.-H.; Wang, L.-W.; Chang, K.-W.; Lee, G.-B.; Lee, M.-C.M. Application of strong transverse magneto-optical Kerr effect on high sensitive surface plasmon grating sensors. Opt. Express 2014, 22, 19794-19802. [CrossRef] [PubMed]

109. Caballero, B.; García-Martín, A.; Cuevas, J.C. Hybrid magnetoplasmonic crystals boost the performance of nanohole arrays as plasmonic sensors. ACS Photonics 2016, 3, 203-208. [CrossRef]

110. Grunin, A.; Mukha, I.; Chetvertukhin, A.; Fedyanin, A. Refractive index sensor based on magnetoplasmonic crystals. J. Magn. Magn. Mater. 2016, 415, 72-76. [CrossRef]

111. Maccaferri, N.; Gregorczyk, K.E.; De Oliveira, T.V.; Kataja, M.; Van Dijken, S.; Pirzadeh, Z.; Dmitriev, A.; Åkerman, J.; Knez, M.; Vavassori, P. Ultrasensitive and label-free molecular-level detection enabled by light phase control in magnetoplasmonic nanoantennas. Nat. Commun. 2015, 6, 6150. [CrossRef] [PubMed]

112. Manera, M.G.; Ferreiro-Vila, E.; Garcia-Martin, J.M.; Garcia-Martin, A.; Rella, R. Enhanced antibody recognition with a magneto-optic surface plasmon resonance (MO-SPR) sensor. Biosens. Bioelectron. 2014, 58, 114-120. [CrossRef] [PubMed]

113. Wang, Y.; Dostalek, J.; Knoll, W. Magnetic nanoparticle-enhanced biosensor based on grating-coupled surface plasmon resonance. Anal. Chem. 2011, 83, 6202-6207. [CrossRef] [PubMed]

114. Tseng, P.; Di Carlo, D.; Judy, J.W. Rapid and dynamic intracellular patterning of cell-internalized magnetic fluorescent nanoparticles. Nano Lett. 2009, 9, 3053-3059. [CrossRef] [PubMed]

115. Duan, N.; Shen, M.; Wu, S.; Zhao, C.; Ma, X.; Wang, Z. Graphene oxide wrapped $\mathrm{Fe}_{3} \mathrm{O}_{4} /$ Au nanostructures as substrates for aptamer-based detection of Vibrio parahaemolyticus by surface-enhanced Raman spectroscopy. Microchim. Acta 2017, 184, 2653-2660. [CrossRef]

116. Zhou, X.; Xu, W.; Wang, Y.; Kuang, Q.; Shi, Y.; Zhong, L.; Zhang, Q. Febrication of cluster/shell/ $\mathrm{Fe}_{3} \mathrm{O}_{4} / \mathrm{Au}$ nanoparticles and application in protein detection via a SERS method. J. Phys. Chem. C 2010, 114, 19607-19613. [CrossRef]

117. Han, Y.; Lei, S.L.; Lu, J.H.; He, Y.; Chen, Z.W.; Ren, L.; Zhou, X. Potential use of SERS-assisted theranostic strategy based on $\mathrm{Fe}_{3} \mathrm{O}_{4} / \mathrm{Au}$ cluster/shell nanocomposites for bio-detection, MRI, and magnetic hyperthermia. Mater. Sci. Eng. C 2016, 64, 199-207. [CrossRef] [PubMed]

(C) 2018 by the authors. Licensee MDPI, Basel, Switzerland. This article is an open access article distributed under the terms and conditions of the Creative Commons Attribution (CC BY) license (http:/ / creativecommons.org/licenses/by/4.0/). 